\title{
STRUCTURE AND SOOT PROPERTIES OF NONBUOYANT ETHYLENE/AIR LAMINAR JET DIFFUSION FLAMES*
}

\author{
D.L. Urban, Z.-G. Yuan, P.B. Sunderland \\ NASA Lewis Research Center, Cleveland, Ohio 44135 \\ G.T. Linteris, J.E. Voss \\ NASA Johnson Space Center, Houston, Texas 77058 \\ K.-C. Lin, Z. Dai, K. Sun and G.M. Faeth \\ The University of Michigan, Ann Arbor, Michigan 48109-2140
}

\begin{abstract}
Observations of the structure and soot properties of round, soot-emitting, nonbuoyant, laminar jet diffusion flames are described, based on long-duration (175-230 s) experiments at microgravity carried out on orbit in the Space Shuttle Columbia. Experimental conditions included ethylene-fueled flames burning in still air at nominal pressures of 50 and $100 \mathrm{kPa}$ and an ambient temperature of $300 \mathrm{~K}$ with luminous flame lengths of $49.64 \mathrm{~mm}$. Measurements included luminous flame shapes using color video imaging, soot concentration (volume fraction) distributions using deconvoluted laser extinction imaging, soot temperature distributions using deconvoluted multiline emission imaging, gas temperature distributions at fuel-lean (plume) conditions using thermocouple probes, soot structure distributions using thermophoretic sampling and analysis by transmission electron microscopy (TEM) and flame radiation using a radiometer. After an initial 20s flame stabilization period (caused by effects of ignitor disturbances, fuel flow rate adjustments and transient development of flame structure), the flames reached steady-state conditions aside from slow (quasisteady) changes due to pressure increases and ambient oxygen consumption within the test chamber caused by combustion. The present flames were larger, and emitted soot more readily, than comparable flames observed during ground-based microgravity experiments due to closer approach to truly steady conditions resulting from the longer test times and the reduced gravitational disturbances of the space-based experiments. Increasing the pressure from 50 to 100 $\mathrm{kPa}$ for soot-emitting flames of similar length caused maximum soot volume fractions to increase from 2 to $32 \mathrm{ppm}$ and average primary soot particle diameters to increase from 24 to $40 \mathrm{~nm}$, showing that soot emissions are the result of the relative rates of soot formation and oxidation and do not correlate closely
\end{abstract}

with peak soot concentrations and primary particle sizes within the flames. In addition, comparable sootemitting buoyant laminar diffusion flames at normal gravity and $100 \mathrm{kPa}$ have significantly smaller maximum primary soot particles $(32 \mathrm{~nm}$ diameter implying roughly 50 percent less mass) than the nonbuoyant flames. It was also found that the tipopening phenomena associated with nonbuoyant sootemitting flames is caused by extinction of the flame near its tip due to radiative heat losses, which means that emissions of unburned fuel are associated with emissions of soot in the present nonbuoyant flames. Finally, soot production properties (characterized by maximum soot concentrations) are similar for various paths through the $50 \mathrm{kPa}$ flame where effects of radiative extinction and soot particle thermophoresis are small, suggesting potential for a simple state relationship between soot concentrations and mixing level (mixture fraction) at flame conditions representative of many practical applications. This behavior follows because flame residence times are relatively independent of path for nonbuoyant laminar jet diffusion flames, and may help to explain the universality of many properties of soot emitted from practical flames (which generally are relatively nonbuoyant).

\section{Nomenclature}

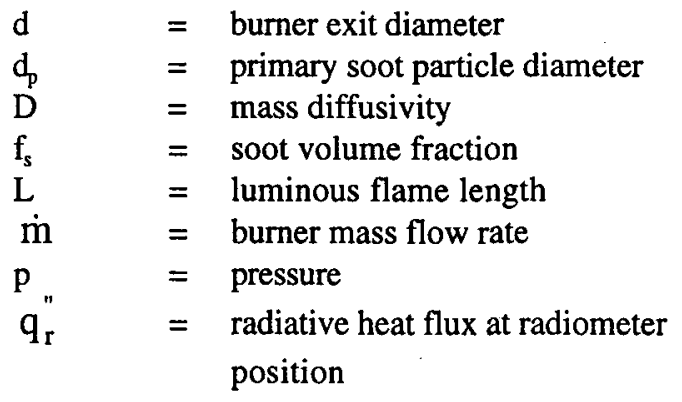

\footnotetext{
* Copyright (C) 1998 by American Institute of Aeronautics and Astronautics, Inc. All rights reserved.
} 


$\begin{array}{lll}\dot{\mathrm{Q}}_{\mathrm{ch}} & = & \text { chemical energy release rate of } \\ & & \text { flame } \\ \dot{\mathrm{Q}}_{\mathrm{r}} & = & \text { radiant heat loss rate of flame } \\ \mathrm{r} & = & \text { radial distance } \\ \mathrm{r}_{\mathrm{r}} & = & \text { distance between radiometer and } \\ & \text { center of flame } \\ \mathrm{R} & =\text { maximum luminous flame radius } \\ \mathrm{Re} & =\text { burner Reynolds number, } \\ & & 4 \dot{\mathrm{m}} /\left(\pi \mathrm{d} \mu_{\mathrm{o}}\right) \\ \mathrm{t}_{\mathrm{ch}} & = & \text { characteristic residence time, } 2 \mathrm{~L} / \mathrm{u}_{\mathrm{o}} \\ \mathrm{t}_{\mathrm{tr}} & = & \text { characteristic transient time, } \mathrm{R}^{2} / \mathrm{D} \\ \mathrm{t} & = & \text { time } \\ \mathrm{T} & = & \text { temperature } \\ \mathrm{u} & = & \text { streamwise velocity } \\ \mathrm{v} & = & \text { radial velocity } \\ \mathrm{z} & = & \text { streamwise distance } \\ \eta & = & \text { radiative heat loss fraction } \\ \mu & = & \text { dynamic viscosity } \\ \mathrm{v} & = & \text { kinematic viscosity } \\ \rho & = & \text { density } \\ \phi & = & \text { fuel-equivalence ratio } \\ \text { Subscripts } & \\ \mathrm{o} & = & \text { burner exit condition } \\ \infty & = & \text { ambient condition } \\ & & \\ & & \text { Introduction }\end{array}$

Overall Objectives and Motivation

An experimental study of soot processes in hydrocarbon-fueled nonbuoyant and nonpremixed (diffusion) flames is described that was carried out at microgravity $(\mu \mathrm{g})$ conditions in space. The study was motivated by the impact of soot on the performance of power and propulsion systems, the hazards of unwanted fires, and emissions of combustion-generated pollutants. For example, deposition of flame-generated soot can foul critical combustor components such as ignitors and injectors, while continuum radiation from soot is the main heat load of combustor components and controls their durability and life. ${ }^{1}$ Continuum radiation from soot also is mainly responsible for the growth and spread of unwanted fires while soot-containing plumes emitted from these flames inhibit fire-fighting efforts. ${ }^{2-4}$ In addition, black exhaust plumes containing particulate soot are an easily-recognized source of combustiongenerated pollutants that will be subjected to increasing regulation in the future. No less problematical are the carbon monoxide and unburned hydrocarbon emissions that intrinsically are associated with emissions of soot (e.g., carbon monoxide emissions are the main cause of fatalities in unwanted fires). ${ }^{5-7}$ Finally, achieving practical methods of computational combustion continues to be frustrated by limited understanding of soot processes within hydrocarbon-fueled flames. Thus, gaining a better understanding of soot processes within flames is widely considered to be a major unresolved problem of combustion science.

\section{Soot Processes in Buoyant and Nonbuoyant Flames}

Soot processes in turbulent diffusion flames are of the greatest practical interest, however, direct study of such flames is not tractable. In particular, the unsteadiness and distortion of turbulent flames limits available residence times and spatial resolution within regions where soot processes are important. This prevents the numerous simultaneous measurements needed to define the reactive and radiative environment of soot, e.g., soot concentration, soot structure, gas composition and temperature. Thus, laminar diffusion flames are generally used as more tractable model flame systems to study processes relevant to turbulent diffusion flames, justified by the known similarities of gas-phase processes in laminar and turbulent flames. ${ }^{8-12}$ Unfortunately, laminar diffusion flames at normal gravity (ng) are affected by buoyancy due to their relatively small flow velocities and, as will be discussed next, they do not have the same utility for simulating soot processes as they do for simulating the gas-phase processes of practical turbulent flames.

Local effects of buoyancy are small in the soot reaction regions of practical turbulent flames; therefore, buoyant laminar diffusion flames can only provide a proper model flame system to the extent that buoyancy does not directly affect soot processes. Unfortunately, because soot particles are too large to diffuse like gas molecules and primarily are convected by local flow velocities (aside from the minor effects of thermophoresis), their behavior in buoyant and nonbuoyant diffusion flames is quite different. ${ }^{11-13}$ This can be seen in Fig. 1, where some features of buoyant and nonbuoyant laminar jet diffusion flames are plotted as a function of streamwise and radial positions. The results for the buoyant flame are based on measurements, ${ }^{14-20}$ while the results for the nonbuoyant flame are based on predictions. ${ }^{21,22}$ Soot formation (nucleation and growth) reactions in diffusion flames occur where fuel-equivalence ratios are in the rangel$2,{ }^{14-16,23,24}$ which is marked on the plots. The dividing streamline, which is the boundary of the cross-section of the flow that has the same streamwise mass flow rate as the burner port (and roughly corresponds to a condition of negligible cross-stream velocity, $v \approx 0$ ), and some typical soot pathlines, are also shown on the plots. 
To interpret Fig. 1, it should be noted that soot convects with the flow velocity and moves toward the dividing streamline in the radial direction, i.e., radial velocities inside and outside the dividing streamline are positive and negative, respectively. Due to flow acceleration within buoyant flames, the dividing streamline moves toward the flame axis with increasing streamwise distance and generally lies inside the soot formation region. In contrast, due to flow deceleration in nonbuoyant flames, the dividing streamline moves away from the flame axis with increasing streamwise distance and generally lies outside of the soot formation region. The different relative positions of the soot formation regions and the dividing streamlines imply rather different soot processes for most of the soot formed in buoyant and nonbuoyant flames. For buoyant flames, most of the soot nucleates near the outer boundary of the soot formation region (near the flame sheet at $\phi=1$ ) and then moves radially inward to cooler and less reactive conditions at larger fuelequivalence ratios for a time before finally crossing the flame sheet near its tip within an annular soot layer in the vicinity of the dividing streamline. In contrast, for nonbuoyant flames, most of the soot nucleates at relatively large fuel-equivalence ratios near the inner boundary of the soot formation region (near $\phi=2$ ) and then moves directly through the flame sheet so that it only experiences a monotonic reduction of fuelequivalence ratio. In addition, velocities along these soot paths progressively increase and decrease with increasing distance along the path for buoyant and nonbuoyant flames, respectively, which implies that soot-formation/soot-oxidation residence time ratios generally are larger for buoyant than nonbuoyant flames. ${ }^{4}$ In view of these considerations, soot processes within buoyant and nonbuoyant laminar diffusion flames clearly are very different, with results for the nonbuoyant laminar diffusion flames representing the soot processes that are of greatest interest for practical turbulent flames (which generally are nonbuoyant due to their large flow velocities).

Other advantages of nonbuoyant laminar diffusion flames for studies of soot processes are that nonbuoyant flames provide better spatial resolution, and more flexible control of flame residence times, than buoyant flames. The improved spatial resolution can be seen from the results illustrated in Fig. 1. In particular, the flame surface and the dividing streamline are close to one another in buoyant flames so that soot processes are confined to a narrow layer. In contrast, soot processes are spread along most of the flame surface for nonbuoyant flames, vastly improving the spatial resolution. Finally, flame residence times for buoyant laminar diffusion flames can only be controlled over a narrow range because flow velocities and mixing rates are dominated by effects of buoyancy; therefore, burner diameter and initial gas velocity variations have little effect. $^{5,6}$ In contrast, changing burner diameters and initial gas velocities for nonbuoyant flames yield corresponding variations of flame residence times, ${ }^{22}$ providing considerable flexibility for studying soot processes in diffusion flames.

In summary, nonbuoyant laminar diffusion flames provide a reasonable simulation of the hydrodynamic environment of soot in practical turbulent diffusion flames. In addition, nonbuoyant laminar diffusion flames have better spatial resolution and flexibility to vary residence times than either buoyant laminar diffusion flames or practical turbulent diffusion flames. These advantages motivated the present interest in studying soot processes in nonbuoyant laminar diffusion flames; in addition, space-based experiments at $\mu \mathrm{g}$ were considered to provide sufficient test times to ensure steady flame conditions for relatively extensive measurements (for a space-based experiment) of flame structure and soot properties.

\section{Previous Studies}

In the following, previous studies of soot processes in laminar diffusion flames and of nonbuoyant laminar diffusion flames at $\mu \mathrm{g}$ will be briefly reviewed, in turn. More extensive reviews of past studies of soot processes and soot structure in flames can be found in Haynes and Wagner, ${ }^{23}$ Glassman, ${ }^{24}$ Howard, ${ }^{25}$ Jullian and Botet, ${ }^{26}$ Kennedy, ${ }^{27}$ and references cited therein. Similarly, more extensive reviews of past studies of nonbuoyant laminar diffusion flames at $\mu \mathrm{g}$ can be found in Law and Faeth, ${ }^{4}$ Kono et al., ${ }^{28}$ and references cited therein.

Recent studies of soot processes in buoyant laminar diffusion flames include. Sunderland and coworkers, ${ }^{14-16}$ Santoro and coworkers, ${ }^{17-20}$ Dobbins and coworkers, ${ }^{37-41}$ Flower and Bowman, ${ }^{42-45}$ Glassman and coworkers $^{24,46}$, Garo et al., ${ }^{47,48}$ and Saito et al., ${ }^{49}$ among others. A popular flame configuration for these studies has been the buoyant laminar jet diffusion flame that is typically used for measurements of laminar smoke point properties. ${ }^{5,46}$ These studies have provided considerable information about the structure of both buoyant laminar jet diffusion flames and soot particles within them, which has been exploited in connection with the discussion of Fig. 1. The most recent studies involve 
rather detailed measurements of velocities, temperatures, concentrations of major gas species, concentrations of soot, and soot structure, along the axes of laminar buoyant jet diffusion flames; these results have helped to identify some properties of soot formation (nucleation and growth) in different flames as well as the relationships between soot formation processes in premixed and diffusion flames. ${ }^{14-16}$ Puri et al. ${ }^{19,20}$ have recently reported similar studies of soot oxidation in laminar jet diffusion flames. Unfortunately, the properties of both the soot and the local reactive environment in all these studies have not yet been sufficiently defined to allow detailed consideration of soot formation and oxidation processes in laminar diffusion flames, comparable to recent studies of laminar premixed flames, see Kennedy, ${ }^{27} \mathrm{Xu}$ et al. ${ }^{50,51}$ and references cited therein for discussions of recent findings concerning soot processes in laminar premixed flames.

Considering detailed chemistry when predicting the structure of soot-containing flames is far too complex to be feasible. A tractable alternative is offered by the well-known observation that the concentrations of major gas species within soot-containing laminar diffusion flames correlates reasonably well as a function of the extent of mixing of the fuel- and oxidantcontaining streams (usually represented by the mixture fraction or fuel-equivalence ratio) ${ }^{8-12}$ These correlations (called state relationships) extend to fuel-rich conditions affected by finite-rate fuel decomposition and soot chemistry for wide ranges of local transport and reaction rates (usually characterized by wide ranges of flame stretch) within typical flames. This behavior implies that state relationships found from relatively simple measurements within laminar diffusion flames can be applied to turbulent diffusion flames, by assuming that the turbulent flames correspond to wrinkled laminar flames. This approach is called the laminar flamelet concept or conserved-scalar formalism. ${ }^{8}$

There is indirect evidence from measurements within strongly turbulent diffusion flames (having small local effects of buoyancy) that laminar flamelet concepts may also apply to the soot properties of strongly turbulent diffusion flames..$^{5-7,52-54}$ If this proves to be true, the resulting state relationships for soot concentrations, soot structure, and soot optical properties would vastly simplify models of the structure and radiation properties of practical soot-containing turbulent diffusion flames. Part of this evidence comes from observations within the fuel-lean region of large buoyant turbulent diffusion flames (that have small local effects of buoyancy even though the gas motion as a whole is due to buoyancy); these results show that soot structure is uniform and soot concentrations are proportional to the degree of mixing, implying remarkably similar behavior at all points along the transient and wrinkled flame sheet. ${ }^{5-7,52,53}$ Measurements of soot concentration/temperature correlations in the fuel-rich region of similar buoyant turbulent diffusion flames also support the existence of state relationships for soot properties in these flames. ${ }^{54}$ Unfortunately, corresponding attempts to develop state relationships for soot structure and concentrations based on measurements within buoyant laminar diffusion flames, in the same way that such flames are used to find state relationships for major gas species concentrations, have not been successful. ${ }^{11,12}$ This difficulty has been attributed to the differences between soot processes within nonbuoyant and buoyant laminar diffusion flames discussed in connection with Fig. $1 ;{ }^{4}$ however, definitive proof of this hypothesis has been frustrated by the absence of detailed measurements of flame structure and soot properties within truly steady and nonbuoyant laminar diffusion flames. ${ }^{13-16}$

Past studies of nonbuoyant laminar diffusion flames at $\mu \mathrm{g}$ include Cochran and coworkers, ${ }^{55,56}$ Edelman et al., ${ }^{57}$ Klajn and Oppenheim, ${ }^{58}$ Bahadori and coworkers, ${ }^{59-63}$ Sunderland et al., ${ }^{13}$ and references cited therein. The emphasis of the earliest studies was to evaluate methods of predicting flame structure..$^{55-59}$ Experiments completed for these studies were mainly based on free-fall facilities which provide nonbuoyant flame conditions at $\mu \mathrm{g}$ for test times up to $5 \mathrm{~s}$. It was found that predictions based on both simple boundary layer approximations as well as detailed multidimensional numerical simulations all were capable of correlating measurements of luminous flame lengths, in spite of uncertainties about effects of unsteady flame development and glowing soot particles in the fuel-lean portions of the flames.

The most recent studies of nonbuoyant laminar jet diffusion flames have concentrated on observations of soot processes. ${ }^{13,60-63}$ An interesting property of these flames, not seen for buoyant laminar jet diffusion flames, is that the flame tip is pointed when the flame is not emitting soot but becomes blunt (opens) at the onset of soot emissions. This tip-opening phenomenon has been attributed to effects of radiation, soot formation and thermophoretic motion of soot particles. $^{60-63}$ Corresponding measurements of soot brightness temperatures show rather low values in the tip-opened region of nonbuoyant soot emitting flames, supporting the idea that continuum radiation from soot 
is responsible for the tip-opening phenomena by causing the flame to extinguish. ${ }^{60-63}$

The laminar smoke point properties of nonbuoyant laminar jet diffusion flames have also been measured in order to help predict possible soot emissions for some space-based experiments. ${ }^{13}$ These measurements were carried out using aircraft-based facilities to provide test times up to $20 \mathrm{~s}$ at low gravity in order to reduce effects of flame development uncertainties. Considerable differences between the laminar smoke point properties of nonbuoyant and buoyant flames were observed, which is not surprising based on the discussion of Fig. 1. Unfortunately, aircraft facilities provide rather disturbed low-gravity environments while gravitational disturbances and soot emissions were strongly correlated; this caused concerns about whether these results were representative of the behavior of truly steady nonbuoyant laminar jet diffusion flames.

\section{$\underline{\text { Specific Objectives }}$}

The discussion of past research indicates that there are several issues concerning the structure and soot properties of nonbuoyant laminar jet diffusion flames that merit further consideration, as follows: have existing measurements of flame shapes been influenced by unsteady flame development effects due to limited test times at $\mu \mathrm{g}$ ? have existing measurements of laminar smoke point properties been affected by disturbances of the $\mu \mathrm{g}$ environment? what is the relationship between flame structure, soot properties and laminar smoke point properties? what is the nature of the tip-opening process seen at the onset of soot emissions and is it associated with radiative heat losses from the flame? and do nonbuoyant flames at $\mu \mathrm{g}$ have properties consistent with the existence of state relationships for soot properties that are not seen in buoyant laminar diffusion flames at ng due to the intrusion of buoyancy? The present investigation sought to address these issues, based on long-term experimental observations of nonbuoyant laminar jet diffusion flames at $\mu \mathrm{g}$ carried out on orbit in the Space Shuttle Columbia. The specific objectives of the study were as follows:

(1) Develop an experimental apparatus capable of observations of steady nonbuoyant round laminar jet diffusion flames involving hydrocarbon fuels burning in still air at $\mu \mathrm{g}$ for various pressures $(35-130 \mathrm{kPa}$ ), burner diameters (1.6 and $2.7 \mathrm{~mm}$ ) and flame lengths (up to 80 $\mathrm{mm})$.

(2) Complete measurements of flame structure and soot properties, including visible flame shapes, soot concentration distributions, soot temperature distributions, soot structure distributions, plume temperature distributions and flame radiative heat losses.

(3) Exploit the measurements to address the issues mentioned earlier by finding: luminous flame shapes, laminar smoke point properties, relationships between soot concentrations in the flames and laminar smoke point properties, soot concentrations and temperatures during tip opening, and the potential for state relationships for soot properties within nonbuoyant diffusion flames.

The present discussion will mainly focus on a description of experimental methods and findings from the first flight of the apparatus (denoted the Laminar Soot Processes, LSP, Apparatus) on the orbiter (flight STS-83) which was abbreviated due to a fuel-cell malfunction. This involved two soot-emitting ethylene/air flames at nominal pressures of 50 and 100 $\mathrm{kPa}$, respectively. Although few in number, these tests were extensively instrumented and they do provide useful information concerning the research issues mentioned earlier. Nineteen subsequent tests during the second flight of LSP on the orbiter (flight no. STS-94) covered a broader range of conditions but mainly addressed non-soot-emitting flames and will be reported subsequently.

The following description of the study begins with a description of experimental methods. Results are then discussed considering flame development properties, flow visualization, luminous flame lengths, laminar smoke point properties, soot structure properties, soot concentration distributions and flame temperature distributions, in turn.

\section{Experimental Methods}

\section{Apparatus}

The test arrangement consisted of a laminar jet diffusion flame stabilized at the exit of a round fuel nozzle and extending along the axis of a windowed cylindrical chamber as illustrated in Fig. 2. The chamber had a diameter of $400 \mathrm{~mm}$, a maximum length of $740 \mathrm{~mm}$, an internal volume of $0.082 \mathrm{cu}-\mathrm{m}$ and was capable of carrying out laminar diffusion flames tests at pressures in the range $30-130 \mathrm{kPa}$. The end of the 
chamber was sealed with an O-ring/V-band system to provide access to interior components. The chamber was fitted with six fused-silica windows of which three were used by the LSP experiment, as follows: two windows having viewing diameters of $100 \mathrm{~mm}$, mounted opposite one another, for laser extinction measurements; and one window having a viewing diameter of $150 \mathrm{~mm}$ for multiline temperature imaging measurements and for color video of the flame. The chamber was filled with an oxygen/nitrogen mixture to provide the nominal composition of dry air $(21 \pm 1 \%$ oxygen by volume) while the total oxygen consumption during a flame test did not exceed $10 \%$ by volume. Combustion products were vented to space after appropriate processing to satisfy NASA venting requirements.

Two interchangeable fuel nozzles were provided that consisted of constant diameter cylindrical stainless steel tubes having inside diameters of 1.6 and $2.7 \mathrm{~mm}$, wall thicknesses of $0.28 \mathrm{~mm}$ and lengths of $148 \mathrm{~mm}$ from the inlet plenum (Only the $1.6 \mathrm{~mm}$ diameter fuel nozzle was used, however, due to the shortened mission.). The inlets of these tubes had four-passage (cross-configuration) flow straighteners with length-todiameter ratios of $8: 1$ to eliminate swirl in the flow. The overall length-to-diameter ratios of the nozzles themselves were in the range 59-60, which were sufficient to yield fully-developed laminar pipe flow at the nozzle exits for the present test conditions ( $\mathrm{Re}=$ 141). The test fuels were stored in cylinders and delivered to the fuel nozzles through a pressure regulator, solenoid valves and a mass flow rate controller/sensor. The flames were ignited by a hot wire coil that could be retracted from the nozzle exit once ignition was successful. Ignition was detected from the change of resistance of the hot wire and from the output of a radiometer positioned to view the flame. Fuel flow rates at ignition were established at $30 \%$ above the final test values, based on tests at $\mu \mathrm{g}$ using a free-fall facility. After ignition was confirmed, the fuel flow rate was automatically adjusted to the nominal test value. The crew could subsequently adjust the fuel flow rate up to $\pm 30 \%$, in $5 \%$ steps, in order to achieve desired final flame conditions.

Several measurements were made to monitor flame operation, as follows: fuel flow rate using the mass flow rate controller with an accuracy of $0.8 \%$ of the reading; fuel temperature, measured using a thermocouple in the fuel nozzle plenum with an accuracy of $\pm 1.5 \mathrm{~K}$; chamber pressure measured using a pressure transducer with an accuracy of $\pm 1.2 \%$ of the reading; chamber ambient gas temperatures using two thermisters, with an accuracy of measurements of \pm 1.0 $\mathrm{K}$; and flame radiation using a Medtherm 64 series heat flux transducer (wavelength range of 130-11000 nm), with an accuracy of $\pm 4 \%$ of full-scale reading over the range $0-2.2 \mathrm{~kW} / \mathrm{m}^{2}$. All readings were time based and were measured with a frequency no smaller than 1 reading/s. Similar to imaging and thermocouple measurements to be discussed next, all data were stored and downlinked digitally.

\section{Instrumentation}

Laminar flame shapes were measured from video images obtained using a standard color $C C D$ video camera (Hitachi, Model KP-C553). The field of view of the camera was $60 \mathrm{~mm}$ wide $\times 80 \mathrm{~mm}$ long, starting 10 $\mathrm{mm}$ before the nozzle tip, with a depth of field of 25 $\mathrm{mm}$ centered on the nozzle axis. The spatial resolution of the recorded images was better than $0.3 \mathrm{~mm}$. One difficulty with this camera, however, was that it was not possible for the image brightness to be adjusted on orbit. As a result, it was necessary to select camera settings so that flames having the smallest levels of luminosity, based on tests at $\mu \mathrm{g}$ using a free-fall facility, could still be observed. This implied that flame images were somewhat overexposed in most instances. The flame images were recorded at a rate of 30 frames/s.

Soot volume fraction distributions were obtained by deconvoluting laser extinction images for chord-like paths through the flames, similar to methods used by Sunderland and coworkers. ${ }^{14-16}$ The laser source was a diode laser yielding roughly $1 \mathrm{~mW}$ of optical power at $634 \mathrm{~nm}$ (Sanyo Corp, Model 5DL3038). The laser beam was passed through a custom-made apodizing filter to reduce laser intensity variations to less than $75 \%$ over the field of view (with most of the variation at the periphery of the field of view, well away from the extinction image of soot in the flame) and then expanded and collimated to a $40 \times 50 \mathrm{~mm}$ beam using a parabolic mirror. The transmitted signal was collected by a decollimator and a $3.8 \mathrm{~mm}$ diameter spatial filter that provides a $0.5^{\circ}$ acceptance angle on the optical axis. The signal was then passed through neutral density filters to control total signal levels and a laser line filter ( $1 \mathrm{~nm}$ FWHM) to control flame radiation. The laser signal was recorded using a Panasonic Model No. GP-MF552 CCD video camera. The camera was oriented to provide 302 pixels over the $80 \mathrm{~mm}$ field of view along the flame axis and 484 pixels normal to the flame axis. The laser was adjusted to bring the signal just below saturation for the most intensely illuminated pixels, allowing optimum use of the 8-bit detector. 
Spatial resolution of the imaging system was better than $0.3 \mathrm{~mm}$. Baseline measurements were made before and after each test, to allow corrections of background and instrument effects, and to indicate any changes over the measuring period (there were none).

The laser extinction measurements were reduced assuming that the soot optical properties satisfied the small particle (Rayleigh) scattering approximation, similar to past work. ${ }^{14-16}$. A soot refractive index of $1.57+0.56 \mathrm{i}$ was assumed, based on the measurements of Dalzell and Sarofim, ${ }^{64}$ for consistency with past work, ${ }^{14-16}$ as justified by recent gravimetric measurements of soot volume fractions and in situ measurements of soot refractive indices. ${ }^{50,65}$ Experimental uncertainties of these measurements $(95 \%$ confidence) are estimated to be less than $10 \%$ for $f_{s}>$ $0.1 \mathrm{ppm}$, increasing inversely proportional to $f_{s}$ for values smaller than 0.1 .

Soot temperature distributions were obtained by deconvoluting spectral radiation intensities for chordlike paths through the flames, similar to methods used by Sunderland and coworkers, ${ }^{14-16}$ This involved consideration of the line pair at $650 / 850 \mathrm{~nm}$. The flame images were observed using two Panasonic No. GPMF552 CCD video camera that observed the flames through interference filters centered at the appropriate wavelength (10 nm FWHM) as well as neutral density filters to control overall signal levels. The two cameras were mounted side by side and a liquid to image the flame. The cameras were oriented to provide 197 pixels over the $80 \mathrm{~mm}$ field of view along the flame axis and 78 pixels over the $20 \mathrm{~mm}$ wide region that includes the soot-containing region. The integration time of each image was controlled in order to fully utilize the range of the 8-bit detectors. The spatial resolution of these imaging systems was better than $0.4 \mathrm{~mm}$. The multiline imaging measurements were reduced assuming that the soot optical properties satisfied the small particle (Rayleigh) scattering approximation, similar to past work. ${ }^{14-16}$ Camera response at the two wavelengths was calibrated over the CCD arrays using a blackbody source. Differences between soot refractive indices at the two wavelengths were small, and were ignored. ${ }^{64}$ Experimental uncertainties (95\% confidence) of these measurements are estimated to be less than $50 \mathrm{~K}$ for temperatures greater than $1200 \mathrm{~K}$.

Soot structure was measured by thermophoretic sampling and analysis by transmission electron microscopy (TEM), similar to earlier work by Sunderland and coworkers, ${ }^{14-16}$ This involves mounting Formvar/carbon-coated copper grids used to hold TEM specimens ( $3 \mathrm{~mm}$ diameter, 200 mesh copper grids coated with a Formvar/carbon film, SPI Supplies, part no. $3420 \mathrm{C}$ ) directly on sampling probes so that they were aligned parallel to the streamwise direction. Four sampling probes were used, located $15,37,59$ and 80 $\mathrm{mm}$ from the burner exit. Four TEM grids were located along each sampling probe with the inner-most grid centered at the flame axis and with $4.2 \mathrm{~mm}$ separation between the centers of the grids. The grids were stored in cylindrical chambers with the probe and cylinder tips located $48 \mathrm{~mm}$ from the flame axis. Insertion and retraction times of the probes were smaller than $18 \mathrm{~ms}$, with sampling periods of $200 \mathrm{~ms}$ providing coverage of the grid surface with soot of less than $30 \%$ to minimize overlapping of soot aggregates. Smaller levels of coverage, less than $10 \%$ similar to past work, ${ }^{14-16}$ would have been desirable but could not be selected because there was no past experience with TEM sampling at these conditions. Fortunately, present measurements were limited to determination of primary soot particle diameters which are not strongly affected by overlapping soot aggregates. In addition, soot aggregate size causes negligible sampling bias for present conditions. ${ }^{66}$

The soot samples were analyzed using a JEOL $2000 \mathrm{FX}$ analytical electron microscope with a $1 \mathrm{~nm}$ edge-to-edge resolution. The images were calibrated with latex spheres having diameters of $91 \mathrm{~nm}$ (with a standard deviation of $5.8 \mathrm{~nm}$ ). The primary particles were nearly monodisperse at a position (standard deviation of primary particle diameters were less than $10 \%$ of the mean), determined by measuring $50-100$ primary particles from 25-50 different aggregates. Experimental uncertainties (95\% confidence) of soot of primary particle diameters were dominated by finite sampling limitations and were less than $10 \%$.

Finally, cross-stream temperature distributions in the plume were measured using a thermocouple array located $190 \mathrm{~mm}$ from the burner exit. Thermocouple spacing in the cross-stream direction was 4.8-5.1 mm with seven thermocouples positioned along one diameter and three thermocouples positioned along a perpendicular diameter. The thermocouple beads had diameters less than $0.20 \mathrm{~mm}$, with bare wire distances between the beads and the sheathed insulators used to mount the wires greater than 9 wire diameters. Unfortunately, soot emitted from the flames deposited on the thermocouple wires making assessment of thermocouple errors problematical; therefore, these measurements are only considered to be qualitative, as discussed later. 


\section{Test Conditions}

The conditions of the present two test flames are summarized in Table 1 . These flames involved ethylene fuel jets burning in still air at nominal pressures of 100 and $50 \mathrm{kPa}$, in turn. The fuel flow rates and burner diameters of both flames were the same so they both had the same Reynolds number, $\operatorname{Re}=141$. Ambient chamber compositions, pressures and temperatures all varied slightly over flame burning periods of 230 and 175s. Both flames were soot emitting, and had luminous flame lengths, $\mathrm{L}$, of 49-64 $\mathrm{mm}$. Characteristic flame residence times were based on the luminous flame length and the average streamwise velocity, $u_{d} / 2$, as follows:

$$
\mathrm{t}_{\mathrm{ch}}=2 \mathrm{~L} / \mathrm{u}_{\mathrm{o}}
$$

The values of $t_{c h}$ are rather large for the present flames, 124 and $78 \mathrm{~ms}$, because very low velocities can be accommodated due to the absence of buoyancy, e.g. most practical flames at ng have characteristic residence times less than $10 \mathrm{~ms}$.

Radiative heat losses from the flames were found by assuming that the radiant heat flux was spherically symmetric, similar to past work: $:^{11,12}$

$$
\dot{\mathrm{Q}}_{\mathrm{r}}=4 \pi \mathrm{r}_{\mathrm{r}}^{2} \mathrm{q}_{\mathrm{r}}^{\prime \prime}
$$

where $r_{r}$ is the distance along the optical axis of the radiometer between the radiometer and the flame axis, noting that the position where the radiometer optical axis and the flame axis cross approximates the center of the flames. The chemical energy release rate of the flame is defined in terms of the lower heating value (LHV) of the fuel, also similar to past work: ${ }^{11,12}$

$$
\dot{\mathrm{Q}}_{\mathrm{ch}}=\dot{\mathrm{m} L H V}
$$

Then the radiative heat loss fraction is defined in the usual manner as

$$
\eta=\dot{\mathrm{Q}}_{\mathrm{r}} / \dot{\mathrm{Q}}_{\mathrm{ch}}=4 \pi \mathrm{r}_{\mathrm{r}}^{2} \mathrm{q}_{\mathrm{r}}^{\prime \prime} /(\dot{\mathrm{m} L H V})
$$

The resulting values of $\eta$ for the present flames are rather large, 60 and $56 \%$, compared with expectations for buoyant laminar ethylene/air flames; ${ }^{11}$ this behavior is caused by the large residence times which imply unusually slow heat release rates to compensate for effects of flame radiation. These large residence times are also responsible for large soot concentrations and primary soot particle diameters, relative to buoyant flames of similar size at ng, as discussed later.

\section{Results and Discussion}

\section{Flame Development}

The general nature of the test flames at normal pressures of 100 and $50 \mathrm{kPa}$ can be seen from the plots of the monitoring measurements illustrated in Figs. 3 and 4 , respectively. The following flame properties are illustrated as a function of time after ignition: ignitor and soot sample timing, fuel flow rate, ambient oxygen concentration (calculated), luminous flame length, maximum luminous flame radius, plume temperature at flame axis, radiant heat flux, ambient chamber pressure and ambient chamber temperature. The ignitor and soot sampler timing refers to hardware actuation conditions. The ignitor system was energized for roughly $11 \mathrm{~s}$, which shifts the hot wire coil to the burner exit at the beginning of the test. The soot samplers are energized for shorter periods than can be seen on the figures ( 200 $\mathrm{ms}$ ) toward the end of the test, with the four activations corresponding to the four soot samplers which are energized one at a time, progressively moving toward the burner exit. It should be noted that images for flame shape, soot concentration, and soot temperature measurements, were obtained during the quasi-steady period at times greater than $18 \mathrm{~s}$ and before operation of the soot samplers.

The results illustrated in Figs. 3 and 4 show that ambient oxygen concentrations (computed assuming complete fuel oxidation) decreased while the ambient chamber pressures and temperatures increased with increasing time. More rapid changes are seen for the flame having the lower nominal pressure, as expected, due to the smaller mass and thermal capacity of the low pressure air within the chamber. It will be seen later that even though these changes of ambient chamber properties are relatively small, they still cause measurable changes of flame properties.

Since the STS- 83 flight was abbreviated due to the fuel-cell problems of the orbiter, the present two test conditions were chosen somewhat conservatively to yield relatively long flames that provided good signalto-noise ratios for measurements. Thus, the plots of Figs. 3 and 4 show that after ignition, in order to minimize soot emissions, the crew reduced fuel flow rates the maximum allowable amount for both flames. In spite of this large adjustment, however, both flames emitted more soot than expected because the flames were somewhat larger, and emitted soot somewhat more 
readily, than anticipated from $\mu \mathrm{g}$ tests using groundbased facilities, as discussed later.

Maximum flame dimensions decrease as the fuel flow rate decreases in Figs. 3 and 4 and finally approach quasi-steady behavior where the flames grow slowly due to changes of chamber conditions over the total test time. The final adjustment to this quasisteady behavior, however, is rather slow. For example, after the last fuel flow rate adjustment, the flame lengths undershoot and then increase in length once again, over a 5-10 s period, before finally approaching quasisteady behavior. This undershoot is largely a result of the interaction between the mass flow controller and an orifice (upstream) that was included to limit the maximum fuel flow rate for safety reasons. The characteristic transient development times of the present flames can be expressed as follows:

$$
t_{t r}=R^{2} / D
$$

where $\mathbf{R}$ is the maximum luminous flame radius. Based on the results plotted in Figs. 3 and 4, $R$ is on the order of $10 \mathrm{~mm}$ for both flames, while representative values of $D$ for transport processes near the periphery of the flame are on the order of 20 and $48 \mathrm{~mm}^{2} / \mathrm{s}$ for the flows at 100 and $50 \mathrm{kPa}$, respectively. Then, Eq. (2) yields $t_{\mathrm{tr}}$ on the order of 5 and $3 \mathrm{~s}$ for the flames at 100 and 50 $\mathbf{k P a}$, which is also comparable to present observations. Evidence just presented suggests that laminar flames typical of present test conditions require relatively long transient development times (aside from system response characteristics) and are best observed during long-term space-based experiments if truly steady and nonbuoyant behavior is desired. Other evidence suggesting rather slow flame development rates can be seen from the effects of the soot sampler disturbances which do not entirely decay away for many properties over the $10 \mathrm{~s}$ intervals between activation of soot samplers. Finally, other supporting evidence of slow flame development times, based on comparisons between the present flames and flames observed for shorter test times using ground-based $\mu \mathrm{g}$ facilities, will be discussed later.

Plume axis temperatures for the flame having a nominal pressure of $100 \mathrm{kPa}$, and radiometer signals for both flames, suggest transient development and quasisteady periods, similar to the other properties just discussed. On the other hand, plume temperatures increase slowly over the entire test period for the flame having a nominal pressure of $50 \mathrm{kPa}$. This behavior is felt to be caused by soot deposition on the thermocouple probes from the heavily-sooting first test at $100 \mathrm{kPa}$, which was evident when the interior components of the chamber were inspected after the second test (the two soot populations on the thermocouple probes could be distinguished by both the amount and the appearance (color) of the soot). Such deposits would be expected to inhibit thermocouple response, leading to the gradually increasing plume temperature signals seen in Fig. 4.

\section{Flow Visualization}

Flame images from the color video camera and the laser extinction observations provide complementary information about the flames by defining regions of flame luminosity and regions containing soot, respectively. This information will be discussed in the following, considering the flames at normal pressures of 100 and $50 \mathrm{kPa}$, in turn.

A video image of the flame at $100 \mathrm{kPa}$ is illustrated in Fig. 5. This image was obtained at quasisteady conditions, in the period where laser extinction and multiline temperature images were being obtained, at roughly 170 s after the time of ignition. As noted earlier, fixed camera settings imply that images of the present strongly-luminous flames are overexposed; therefore, the images were adjusted to minimize color distortion due to saturation and reflection from components within the test chamber. As a result, this image provides an indication of regions in the flame having different colors but the image does not provide particularly accurate representation of the actual flame colors. As noted during earlier observations of nonbuoyant round laminar jet diffusion flames at $\mu \mathrm{g},{ }^{55-}$ 57,59-63 these flames are very symmetric, they tend to extend somewhat upstream of the burner exit, and they are very steady with none of the flickering due to buoyant instabilities that is characteristic of buoyant laminar jet diffusion flames at $n g .{ }^{4}$ No soot is present in the region where the flame stabilizes near the burner exit so that this region appears blue. The absence of soot in this region is caused by small residence times, some premixing from quenched air flowing into the flame along the burner tube, and the effects of entrained air sweeping soot particles away from the flame sheet toward the interior of the flow (this region is upstream the dividing streamline and behaves similar to the region downstream of the dividing streamline of buoyant flames discussed in connection with Fig. 1). Significant soot concentrations begin to develop very close to the burner exit in the flame, yielding a brilliantly luminous region that extends over most of the length of the flame. Evidence to be presented later 
will show that the outer radial boundary of this strongly luminous region is just inside the flame sheet, which is not visible itself on the present image. The color changes, abruptly near the flame tip along a line normal to the flame axis; evidence to be presented later strongly suggests that oxidation at the flame sheet is extinguished along this line. Downstream of the extinction region, the glowing soot particles cool rapidly causing luminosity to decrease and flame color to become a deeper red. Finally, the luminous region at the top of the flame ends in a rather blunt shape which is typical of the "tip-opening" behavior of soot-emitting nonbuoyant laminar jet diffusion flames. ${ }^{60-63}$

The evolution of flame shape as a function of time during the quasi-steady period can be seen from the plots of flame boundaries for the flame at a nominal pressure of $100 \mathrm{kPa}$ illustrated in Fig. 6. The luminous and extinction boundaries are plotted in the figure as a function of streamwise and radial distances at the beginning, middle and end of the quasisteady period $(\mathrm{t}=$ 18,90 and $180 \mathrm{~s}$ ). It is evident that the changes of flame boundaries are small over the quasi-steady period, which is consistent with the estimates of simplified theories $^{21}$ of flame shape for the modest changes of ambient conditions over the time period considered.

A typical laser extinction image obtained at the middle of the quasisteady period is illustrated in Fig. 7 for the flame having a nominal pressure of $100 \mathrm{kPa}$. On this image, the flow is from left to right as indicated by the outline of the burner tube at the left of the photograph. The laser extinction signal is weak near the burner exit due to combined effects of the soot-free blue region, relatively small soot concentrations and relatively small path lengths through the flame. The signal strength increases with increasing distance, however, and eventually has very good signal-to-noise ratios. This flame is soot-emitting so that the extinction signal does not end in a blunt tip similar to the laminar flame shape; instead, soot emitted from the flame generates an extinction signal throughout the plume region. The extinction signal is particularly strong near its periphery; results to be considered later will show that this region corresponds to a rather prominent soot layer that is confined and has nearly parallel sides due to effects of thermophoresis caused by the presence of the high-temperature flame sheet just outside the soot-containing region. Thermophoresis is particularly important for this flame because flow velocities become small near the tip of the flame while the nominal pressure level $(100 \mathrm{kPa})$ provides significant thermophoretic velocities.
Similar flow visualization results for the flame at a nominal pressure of $50 \mathrm{kPa}$ are illustrated in Figs. 8-10. A video image of the flame during quasisteady period (130s after the time of ignition) is illustrated in Fig. 8. This flame is somewhat longer, and tip opening is not quite as complete due to reduced rates of soot emission, compared to the video image of the flame at a nominal pressure of $100 \mathrm{kPa}$, illustrated in Fig. 5. Otherwise, however, the video images of the two flames are similar.

The evolution of flame shape as a function of time during the quasisteady period can be seen from the plots of flame boundaries for the flame at a nominal pressure of $50 \mathrm{kPa}$ illustrated in Fig. 9. An interesting feature of these results is the progressive development of tip opening as the ambient oxygen concentration decreases and the pressure increases as a function of time. Thus, this flame was initially borderline sootemitting with the degree of soot emission progressively increasing with increasing time. Similar to effects of fuel flow rates on tip opening seen by Sunderland et al., ${ }^{13}$ tip opening occurs as the result of rather modest changes of flame operating conditions, which make this phenomena a helpful indication of the onset of soot emissions, i.e., the laminar smoke point.

A typical laser extinction image obtained at the middle of the quasisteady period is illustrated in Fig. 10 for the flame at a nominal pressure of $50 \mathrm{kPa}$. As will be seen later, concentrations of soot in this flame are roughly an order of magnitude smaller than the high pressure flame, which yields reduced signal-to-noise ratios in Fig. 10 compared to Fig. 7. As before, this flame is soot-emitting, with a relatively open tip at the time this image was obtained, so that laser extinction continues in plume region. One rather different feature of the laser extinction image of the flame at $50 \mathrm{kPa}$ compared to the flame at $100 \mathrm{kPa}$, is that the extinction signal tends to be strongest near the flame axis, rather than near the periphery. It will be seen that this behavior follows due to much less prominent annular soot layers; in particular, effects of thermophoresis are smaller due to larger flow velocities and smaller thermophoretic velocities at the lower pressure.

\section{Luminous Flame Length}

The luminous flame length is an important property of laminar jet diffusion flames because it helps define the region where flame structure and soot properties can be measured while also playing a critical role in the definition of laminar smoke point properties. It is well known that the luminous flame lengths of 
buoyant laminar jet diffusion flames can be correlated as a simple function of fuel mass flow rate for a given fuel and ambient oxygen condition; ${ }^{4,22,55-63}$ therefore, the performance of this type of correlation for results from both ground-based and space-based experiments will be considered in the following.

Measurements of luminous flame lengths of ethylene/air laminar jet diffusion flames are plotted as a function of fuel flow rate in Fig. 11. Three types of measurements are illustrated in the figure: measurements of buoyant flames at $12-50 \mathrm{kPa}$ using 1.6 and $2.7 \mathrm{~mm}$ burner diameters (burner diameter, however, does not have a large effect on luminous flame lengths at these conditions), measurements of nonbuoyant flames at 50 and $100 \mathrm{kPa}$ using 1.6 and 2.7 $\mathrm{mm}$ burner diameters for nonbuoyant conditions provided by ground-based aircraft $\mu \mathrm{g}$ facilities, and the present two test results for nonbuoyant space-based $\mu \mathrm{g}$ conditions. Typical of earlier observations, ${ }^{4,22,55-63}$ the buoyant flames yield an excellent correlation of luminous flame lengths as a function of fuel mass flow rate for laminar flows at various pressures and burner diameters.

The measurements of luminous flame lengths for the nonbuoyant flames using aircraft $\mu \mathrm{g}$ facilities in Fig. 11 exhibit somewhat greater scatter than the buoyant flame results; this behavior is felt to be due to effects of gravitational disturbances typical of aircraft $\mu \mathrm{g}$ facilities. In spite of the scatter, however, this simple correlation in terms of fuel flow rate provides reasonably good treatment of effects of both burner diameter and pressure. The KC-135 flame correlation also yields (at $95 \%$ confidence) a significant $(40 \%)$ increase of luminous flame lengths compared to the buoyant flame correlation. In this case, the good correlation between luminous flame lengths and fuel flow rates for various pressures and burner diameters can be anticipated based on the predictions of simplified analysis of laminar nonbuoyant jet diffusion flames. ${ }^{21}$

The final measurements of luminous flame lengths illustrated in Fig. 11 are from the present tests at $\mu \mathrm{g}$ using space-based facilities. These results are limited to just two tests with soot-emitting flames but these results yield longer luminous flame lengths than the mean results using ground-based $\mu \mathrm{g}$ facilities, e.g., roughly $27 \%$ longer than the ground-based $\mu \mathrm{g}$ measurements and $82 \%$ longer than the buoyant flame results. Flame disturbances typically enhance mixing and tend to reduce flame lengths which explains the shorter lengths of the more disturbed $\mu \mathrm{g}$ flames using aircraft facilities than the present measurements. In somewhat the same way, velocity increases of the flame gases due to buoyancy also enhances mixing rates which explains why the buoyant flames are generally shorter than the rest. Finally, the rather significant effects of disturbances on the luminous flame lengths of nonbuoyant laminar jet diffusion flames, combined with the relatively slow rate of development of these flames toward quasi-steady conditions, highlights the need for relatively long term tests in the stable $\mu \mathrm{g}$ environment of space-based facilities in order to develop reliable information about the structure and mixing properties of nonbuoyant laminar jet diffusion flames.

Laminar Smoke Point Flame Lengths

Laminar smoke point flame lengths are an important observable soot property of laminar jet diffusion flames. There also is interest in this property for nonbuoyant flames because excessive soot emissions could compromise experiments, such as the present laminar jet diffusion flame tests, by fouling test chamber components. Thus, laminar smoke point properties will be considered in the following.

The present flames were soot-emitting and it was not possible to reduce fuel flow rates sufficiently to accurately identify laminar smoke point flame properties, i.e., luminous flame length and fuel flow rate at incipient sooting conditions. Nevertheless, present observations were not far from laminar smoke point conditions for the flame at a nominal pressure of $50 \mathrm{kPa}$, based on the tip opening behavior of the flame illustrated in Fig. 9. In addition, the present luminous flame lengths for the flame at a nominal pressure of 100 $\mathrm{kPa}$ at least provides an upper bound for the laminar smoke point flame length at this condition. Thus, it is useful to compare present observations with earlier observations of laminar smoke point flame lengths of ethylene/air flämes.

Table 2 is a summary of laminar smoke point flame lengths for round ethylene/air flames. Present results for nonbuoyant flames at $\mu \mathrm{g}$ involve a burner diameter of $1.6 \mathrm{~mm}$, and pressures of 50 and $100 \mathrm{kPa}$, with the results noted as limits as just discussed. The more extensive nonbuoyant flame results of Sunderland et al. ${ }^{13}$ involved ground-based tests at $\mu \mathrm{g}$ using aircraft facilities for burner diameters of 1.6, 2.7 and $5.9 \mathrm{~mm}$ and pressures of 50,100 and $200 \mathrm{kPa}$. Finally, results for buoyant flames were obtained from Schug et al. ${ }^{46}$ and Sivathanu and Faeth ${ }^{54}$ for a burner diameter of 10.0 $\mathrm{mm}$ at $100 \mathrm{kPa}$, although effects of burner diameter on the laminar smoke point properties of buoyant flames are small, as noted earlier. 
An obvious feature of the results summarized in Table 2 is that the laminar smoke point flame lengths of the nonbuoyant flames are significantly smaller than those of the buoyant flames. The nonbuoyant flames have unusually large residence times compared to buoyant flames, as discussed in connection with Table 1. This provides extended periods for soot growth but without corresponding extension of the soot oxidation period due to the flame quenching.

Another interesting aspect of the results summarized in Table 2, is that the laminar smoke point flame length observed at $50 \mathrm{kPa}$ is significantly shorter for the present tests than the results obtained using aircraft $\mu \mathrm{g}$ facilities (corresponding results at $100 \mathrm{kPa}$ are not definitive). This behavior is felt to be due to closer approach to steady and nonbuoyant flame properties compared to the relatively disturbed $\mu \mathrm{g}$ environment of aircraft facilities, as discussed earlier.

\section{Soot Structure}

Typical TEM images of soot particles within the flames at nominal pressures of 100 and $50 \mathrm{kPa}$ are illustrated in Figs. 12 and 13, respectively. As noted earlier, insertion of the soot samplers caused a significant cross-stream disturbance of the flame so that radial variations of sample properties are not very reliable and will not be specified in the following. The images illustrated in Figs. 12 and 13 were obtained from the plume region of the flames at the first sampling station beyond the luminous flame tip: at $\mathrm{z}=$ $59 \mathrm{~mm}$ for the $100 \mathrm{kPa}$ flame in Fig. 12 and $\mathrm{z}=80$ $\mathrm{mm}$ for the $50 \mathrm{kPa}$ flame in Fig. 13. It should be noted that the magnification used in Fig. 13 is 2.5 times larger than the magnification used in Fig. 12.

The soot aggregates illustrated in Figs. 12 and 13 are similar to soot sampled from buoyant diffusion flames, see Refs. 67-69 and references cited therein. This involves roughly spherical primary soot particles that have nearly uniform diameters at any given position in the flame. The primary soot particles are collected into open structured and branched aggregates that have rather large variations of the number of primary soot particles per aggregate (typically represented by $\log$ normal distributions). ${ }^{68,69}$ The images shown in Figs. 12 and 13 are representative of larger soot aggregates emitted from the two flames: the aggregate in Fig. 12 for the $100 \mathrm{kPa}$ flame has a mean primary particle diameter of $39 \mathrm{~nm}$ and a maximum aggregate dimension of $1100 \mathrm{~nm}$ while the aggregate in Fig. 13 for the $50 \mathrm{kPa}$ flame has a mean primary particle diameter of $22 \mathrm{~nm}$ and a maximum aggregate dimension of $600 \mathrm{~nm}$. Thus, decreasing the pressure results in a significant reduction of primary particle mass (a roughly 6:1 reduction in the present case) and a rather significant increase in the degree of aggregation of the particles. The size of the present primary soot particles in the $100 \mathrm{kPa}$ flame is also significantly larger than the primary particles emitted from large ethylene/air buoyant diffusion flames at $\mathrm{ng}$ (that are roughly $32 \mathrm{~nm}$ in diameter, ${ }^{68,69}$ which implies a $2: 1$ reduction of mass compared to the present flame). The effect of pressure is due to the strong effect of pressure on soot formation rates in laminar jet diffusion flames. 14,15 The effect of buoyant condition also is not unexpected because the nonbuoyant flames have significantly larger residence times than typical buoyant flames, which provides time for extensive soot growth and aggregation, without compensating increases of time for soot oxidation due to the tendency for soot oxidation processes to be quenched near the flame tip.

Primary soot particle diameters are summarized as a function of distance from the burner exit for the two flames in Table 3. The values shown are averaged over the cross-section of the flame as noted earlier. This tends to emphasize soot that approaches conditions where it is emitted from the flames due to the rapid nucleation near the inner edge of the soot formation region of typical laminar diffusion flames. ${ }^{14,15}$ In addition, it should be noted that soot was only observed at the first two sampling grids centered at radii of 0 and $4.2 \mathrm{~mm}$ from the flame axis, except for the $50 \mathrm{kPa}$ flame at $\mathrm{z}=59 \mathrm{~mm}$ where soot was also observed at the third sampling grid centered at a radius of $8.4 \mathrm{~mm}$ from the axis. This tendency for soot to be confined in the radial direction will be considered more quantitatively later when distributions of soot volume fractions are discussed. Rather uniform mean particle sizes are seen at each distance from the burner exit, except very near the burner exit (upstream of the dividing streamline) where no soot was observed at all for the $50 \mathrm{kPa}$ flame. This uniformity of primary soot particle diameters for various paths through the flames (downstream of the dividing streamline) is supportive of potential universal state relationships for soot properties in nonbuoyant laminar diffusion flames, as discussed earlier. In addition, rather different behavior of soot processes upstream and downstream of the dividing streamline might be anticipated, based on the discussion in connection with Fig. 1, helping to explain the different behavior of the first station downstream of the burner exit for the $50 \mathrm{kPa}$ flame. 


\section{$\underline{\text { Soot Concentrations }}$}

The measurements of soot structure provide justification for adopting the Rayleigh scattering approximation for analyzing laser extinction measurements to determine soot volume fraction distributions. In particular, soot primary particle optical diameters (based on the mean primary particle diameter of $40 \mathrm{~nm}$ for the $100 \mathrm{kPa}$ flame summarized in Table 1) are less than 0.20 so that effects of scattering on estimates of soot volume fraction are small compared to uncertainties of these estimates due to the uncertainties about the refractive indices of soot. ${ }^{68,69}$

Present measurements of the radial distributions of soot volume fractions at various distances from the burner exit are illustrated in Figs. 14 and 15 for the flames burning at nominal pressures of 100 and $50 \mathrm{kPa}$, respectively. These measurements were obtained during the quasi-steady period with soot volume fraction distributions given at the beginning and end of this period so that effects of chamber property changes can be seen: distributions are shown for times of 90 and $170 \mathrm{~s}$ after ignition for the $100 \mathrm{kPa}$ flame, and for times of 90 and 130s after ignition for the $50 \mathrm{kPa}$ flame. In both cases, the soot concentration profiles tend to become broader, with somewhat reduced peak soot concentrations, as time increases. This behavior is expected as a result of moderately reduced ambient oxygen concentrations due to oxygen consumption by the flame. Another trend of the soot concentration measurements illustrated in Figs. 14 and 15 is the substantial increase of soot concentrations with increasing pressure for otherwise relatively similar flames, with maximum soot concentrations increasing from roughly 2 to $32 \mathrm{ppm}$ for an increase of pressure from 50 to $100 \mathrm{kPa}$. This behavior is consistent with earlier observations of significant increases of soot formation rates with increasing pressure in laminar diffusion flames. ${ }^{14-16,42-45}$

Another feature of the results for the $100 \mathrm{kPa}$ flame illustrated in Fig. 14 is that all the soot at each cross-section of the flame is contained within a narrow annular ring and soot is never observed along the axis of the flame. This behavior appears to be a unique feature of nonbuoyant laminar jet diffusion flames that is associated with the tip-opening phenomenon. In particular, measurements to be discussed subsequently suggest that the flame is quenched near its tip due to continuum radiation heat losses from soot. This implies relatively small temperatures along the flame axis. As a result, the fuel does not decompose near the axis and subsequent soot reaction processes do not occur, indicating that soot emissions are responsible for significant unburned hydrocarbon emissions from tipopened flames.

Other interesting features of the soot concentration distributions illustrated in Fig. 14 for the $100 \mathrm{kPa}$ flame are the rather straight sides of the sootcontaining region and the progressively increasing maximum soot concentrations with increasing distance from the burner exit. As discussed earlier in connection with Fig. 7, thermophoresis due to the presence of a diffusion flame just outside the sootcontaining region acts to impede the radial transport of soot. This effect is particularly important near the tip of the $100 \mathrm{kPa}$ flame because radial flow velocities become relatively small in this region. ${ }^{22}$ Similar effects of thermophoresis are not important for buoyant diffusion flames at $100 \mathrm{kPa}$ and $\mathrm{ng}$ because buoyancyinduced flow velocities near the flame tip are relatively large. ${ }^{54}$ Thus, the inward transport of thermophoresis counterbalances the outward convection of soot so that the soot becomes trapped within a cylindrical region for the high pressure flame; therefore, soot accumulates within a finite radius and its concentration progressively increases with increasing streamwise distance, as seen in Fig. 14.

Taken together, the previous observations concerning soot concentrations for the $100 \mathrm{kPa}$ flame illustrated in Fig. 14 demonstrate that this flame will not yield a soot concentration (or soot volume fraction) state relationship required by the laminar flamelet concept. The reason for this behavior can be seen by noting that the mixture fraction is unity at the burner exit, zero in the unreacted air far from the burner, and monotonically decreases along any smooth path between these two limits. Thus, straight paths from the burner through the maximum soot concentration condition at each streamwise distance from the burner exit illustrated in Fig. 14 involves progressively increasing maximum soot concentrations as the streamwise distance increased. On the other hand, paths near the axis are in the soot-free region and never encounter a finite soot volume fraction. Clearly, soot volume fraction distributions as a function of mixture fraction for these varying paths would differ considerably and this lack of universality would preclude the existence of a soot volume fraction state relationship for this condition. Based on the previous discussion, state relationships are not possible at this condition for two main reasons, as follows: (1) the tipopening phenomenon which is caused by radiative extinction of reactions in the flame sheet, and (2) the thermophoretic phenomenon that impedes radial 
transport of soot particles due to the small flow velocities within the flame. Neither of these phenomena, however, is relevant to practical diffusion flames at $100 \mathrm{kPa}$, for the following reasons: (1) practical diffusion flames have much smaller characteristic residence times, and thus much smaller radiative heat losses, so that radiative extinction yielding tip-opening behavior does not occur, and (2) flow velocities are much larger, which precludes significant thermophoretic effects for soot particles.

In contrast to the findings for the $100 \mathrm{kPa}$ flame, the $50 \mathrm{kPa}$ flame operated at conditions that provided a better simulation of practical diffusion flames, and yields results that are more supportive of the potential existence of soot volume fraction state relationships. In particular, this flame only exhibits relatively weak tip-opening behavior and there is no indication that reactions were fully quenched along the axis, i.e., significant soot concentrations develop along the axis of the flame. In addition, thermophoretic velocities are reduced (by a factor of roughly two ${ }^{66}$ while flow velocities are increased (by roughly a factor of two $)^{22}$ so that capabilities for thermophoretic trapping of soot are much smaller as well. The effect of these changes is that most paths from the burner exit to the ambient environment exhibit nearly the same maximum soot concentration (in the range 1.5-2.0 ppm), which at least satisfies a necessary condition for the existence of a soot volume fraction state relationship for this flame condition. An exception to this behavior is the first streamwise position illustrated in Fig. $15, z=20 \mathrm{~mm}$, where the maximum soot concentration $(0.7 \mathrm{ppm})$ is roughly half that of the other paths. This behavior corresponds to well known exceptions to state relationships for major gas species that are associated with points of flame attachment, ${ }^{54}$ except slower soot kinetics places the region of onset of soot formation farther downstream of the burner. Another factor influencing soot concentrations near the burner exit is the rather different convection pattern of soot particles upstream of the dividing streamline compared to the rest of the flow, as discussed in connection with Fig. 1. Nevertheless, the bulk of the flame is not influenced by these effects and exhibits potential for the existence of soot concentration state relationships, pending computation of mixture fractions and direct observations of soot volume fraction state relationships.

\section{Temperature Distributions}

Present measurements of radial distributions of soot temperatures at various distances from the burner exit are illustrated in Figs. 16 and 17 for the flames burning at nominal pressures of 100 and $50 \mathrm{kPa}$, respectively. Soot concentration distributions and the luminous flame radius at these same positions are also shown on the plots, for reference purposes. Present determinations of soot temperatures are only possible where reasonable levels of soot concentrations and temperatures are present. Two sets of distributions are shown on these figures, similar to the soot concentration results illustrated in Figs. 14 and 15, namely: distributions at $t=90$ and 170 s after the time of ignition for the $100 \mathrm{kPa}$ flame and $\mathrm{t}=90$ and $130 \mathrm{~s}$ after the time of ignition for the $50 \mathrm{kPa}$ flame. The effect of increased time on the temperature distributions is to decrease maximum temperatures and broaden temperature profiles, slightly. Such changes are expected due to reduced ambient oxygen concentrations as combustion proceeds, as noted in connection with Figs. 14 and 15.

In general, soot temperatures progressively increase in the radial direction when there is a reasonably well defined soot layer near the periphery of the flow in Figs. 16 and 17. This behavior suggests the presence of a flame sheet just outside the soot layer at moderate streamwise positions as discussed in connection with the flow visualization results of Figs. $5-10$. This behavior changes as the tip of the $50 \mathrm{kPa}$ flame is approached. Then, the temperature distribution tends to be relatively flat, suggesting that the flame sheet is well within the soot-containing region with soot concentrations decreasing due to soot oxidation near the edge of the flame. The positions of the luminous flame boundary also support this view; for example, the luminous flame boundary is associated with the edge of the soot-containing region at the lower positions but moves into the soot-containing regions at higher positions.

Another general trend seen in the soot temperature results illustrated in Figs. 16 and 17 is that soot temperatures progressively decrease with increasing streamwise distance. This behavior follows because radiative heat losses tend to increase with increasing streamwise distance while at the same time rates of chemical energy release tend to decrease due to reduced concentration gradients as the flame structure develops. As a result, soot temperatures become relatively small as the flame tip is approached; in fact, extrapolating maximum soot temperatures of both flames in the streamwise direction to the extinction boundaries illustrated in Figs. 6 and 9 yields temperatures of roughly $1000 \mathrm{~K}$ with corresponding low reaction rates at such temperatures consistent with extinction. This 
substantiates the earlier assertion that the flame tip is extinguished and unreacted fuel is escaping from the flame along its axis. As noted earlier, Bahadori et al. ${ }^{62,63}$ reach similar conclusions for nonbuoyant tipopened diffusion flames at $\mu \mathrm{g}$ based on measurements of brightness temperatures.

Plume temperature distributions also provide information about relative radiative heat loss phenomena and extinction in the present flames. Thus, measurements of these distributions are illustrated for the 100 and $50 \mathrm{kPa}$ flames in Fig. 18. Two measured distributions are presented for each flame, representative of conditions at the beginning and end of the quasisteady periods, i.e., $t=88$ and 175 s for the $100 \mathrm{kPa}$ flame and $t=89$ and 130 s for the $50 \mathrm{kPa}$ flame. As noted earlier, variations of flame properties over the quasisteady period are not large for the present flames; thus the corresponding changes of the temperature distributions in Fig. 18 are not large compared to experimental uncertainties.

The plume temperatures illustrated in Fig. 18 are larger for the $50 \mathrm{kPa}$ flame than for the $100 \mathrm{kPa}$ flame, these changes are consistent with the increased length and reduced radiative heat losses of the $50 \mathrm{kPa}$ flame. A rather surprising feature of these results, however, is that plume temperatures are lowest near the axis for the restricted range of radial distance considered in Fig. 18 (note measurements at larger radial distance would yield a maximum temperature condition with subsequent approach to the ambient temperature conditions as radial distance was increased). This type of temperature distribution, however, is consistent with flame extinction near the axis in the region of tip opening.

\section{Conclusions}

The structure and soot properties of round, soot-emitting, nonbuoyant, laminar jet diffusion flames were studied experimentally. Test conditions involved ethylene-fueled flames burning in still air at nominal pressures of 50 and $100 \mathrm{kPa}$ and ambient temperatures of roughly $300 \mathrm{~K}$ to yield luminous flame lengths of 49-64 mm. The experiments were carried out at $\mu \mathrm{g}$ with long test durations (175-230s) in order to insure that truly nonbuoyant and steady laminar diffusion flames were observed. The major conclusions of the study are as follows:

1. Transient development of the present flames to quasi-steady conditions (involving variations of flame shape due to gradual oxygen consumption within the test chamber) was surprisingly slow for present test conditions, highlighting the importance of adequate test times at $\mu \mathrm{g}$ to attain nearly nonbuoyant and steady flames. Evidence of slow development comes from flow disturbances and from quantitative differences between flame properties observed during the present tests and during earlier short-duration tests at $\mu \mathrm{g}$ (using ground-based facilities).

2. The present nonbuoyant and steady flames at $\mu \mathrm{g}$ were somewhat larger than earlier observations at $\mu \mathrm{g}$ (using ground-based facilities) and at $\mathrm{ng}$, for comparable conditions. In particular, present luminous flame lengths were up to $30 \%$ longer than earlier results at $\mu \mathrm{g}$ (using ground-based facilities) and up to $80 \%$ longer than results at ng.

3. The present nonbuoyant and steady flames at $\mu \mathrm{g}$ emitted soot more readily than earlier observations at $\mu \mathrm{g}$ (using ground-based facilities) and at ng, for comparable conditions. In particular, present laminar smoke point lengths were $35 \%$ shorter than results at $\mu \mathrm{g}$ (using ground-based facilities) and less than one-third as long as laminar smoke point flame lengths at ng.

4. Increasing the pressure from 50 to $100 \mathrm{kPa}$ for flames having comparable lengths caused maximum soot volume fractions to increase from 2 to $32 \mathrm{ppm}$, and mean primary particle diameters to increase from 24 to $40 \mathrm{~nm}$; this highlights the fact that soot emissions (and thus laminar smoke point properties) follow from relative rates of soot formation and oxidation in flames and do not correlate closely with maximum soot concentrations and primary particle sizes. In addition, comparable soot-emitting buoyant laminar diffusion flames at ng have significantly smaller primary particles, probably due to their much shorter characteristic residence times, e.g., primary particles at ng have roughly $50 \%$ less mass than at $\mu \mathrm{g}$ for flames at $100 \mathrm{kPa}$.

5. Present observations show that the tip-opening phenomena associated with long residence time sootemitting flames at $\mu \mathrm{g}$ is caused by extinction of the flame near its tip, confirming earlier findings of Bahadori and coworkers ${ }^{61-63}$ about this effect. Evidence for extinction comes from measurements of temperatures near the flame tip approaching $1000 \mathrm{~K}$, followed by rapid cooling of soot particles, suggesting a region where fuel oxidation is no longer releasing energy to compensate for radiative heat losses. The end of reaction in an annular soot-containing region also implies significant emissions of unburned fuel along the flame axis, along with the emissions of soot. 
6. Finally, results for the $50 \mathrm{kPa}$ flame near incipient tip-opening conditions yielded similar maximum soot concentrations along all paths through the flame. The flame approached conditions where effects of radiative extinction and thermophoresis were relatively small, typical of practical nonbuoyant turbulent diffusion flames, and supports the potential existence of state relationships for soot concentrations at these conditions. It should be noted, however, that the present observations represent only a necessary, not a sufficient, condition for the existence of state relationships for soot concentrations, pending mixture fraction predictions needed for direct assessment of soot volume fraction state relationships.

\section{Acknowledgments}

This research was supported by NASA Grant Nos. NAG3-1245, NAG3-1878 and NAG3-2048 under the overall technical management of Howard B. Ross of the NASA Lewis Research Center. The authors would also like to acknowledge the contributions of R. Hager, A. Over, R. Chucksa and their associates at NASA LeRC to the development and operation of the test apparatus; of T. Vanhooser, M. Robinson and their associates at NASA MSFC to the integration and operation of the experiments; and to R. Crouch, Payload Specialist during STS-83 and -94, who assisted with the assembly of the test apparatus on orbit as well as with the execution of the experiments.

\section{References}

${ }^{1}$ Viskanta, R., and Mengüc, M.P., "Radiation Heat Transfer in Combustion Systems," Prog. Energy Combust. Sci., Vol. 13, 1987, pp. 511-524.

${ }^{2}$ Tien, C. L., and Lee, S. C., "Flame Radiation," Prog. Energy Combust. Sci. Vol. 8, 1982, pp. 41-59.

${ }^{3}$ Faeth, G.M., Gore, J.P., Chuech, S.G., and Jeng, S.-M., "Radiation from Turbulent Diffusion Flames." Annual Review of Numerical Fluid Mechanics and Heat Transfer, Vol. 2, Hemisphere Publishing Corp., Washington, D.C., 1989, pp. 1-38.

${ }^{4}$ Law, C.K., and Faeth, G.M., "Opportunities and Challenges of Combustion in Microgravity," Prog. Energy Combust. Sci., Vol. 20, 1994, pp. 65-113.
${ }^{5}$ Sivathanu, Y.R., and Faeth, G.M., "Soot Volume Fractions in the Overfire Region of Turbulent Diffusion Flames," Combust. Flame, Vol. 81, 1990, pp. 133-149.

${ }^{6}$ Köylü, Ü.Ö., Sivathanu, Y., and Faeth, G.M., "Carbon Monoxide Emissions from Buoyant Turbulent Diffusion Flames," 3rd International Symposium on Fire Safety Science, Elsevier, London, 1991, pp. 625-634.

${ }^{7}$ Köylü, Ü.Ö., and Faeth, G.M., "Carbon Monoxide and Soot Emissions from Liquid-Fueled Buoyant Turbulent Diffusion Flames," Combust. Flame, Vol. 87, 1991, pp. 61-76.

${ }^{8}$ Bilger, R. W., "Reaction Rates in Diffusion Flames," Combust. Flame, Vol. 30, 1977, pp. $277-$ 284.

${ }^{9}$ Faeth, G.M., and Samuelsen, G.S., "FastReaction Nonpremixed Combustion," Prog. Energy Combust. Sci., Vol. 12, 1986, pp. 305-372.

${ }^{10}$ Sivathanu, Y.R., and Faeth, G.M., "Generalized State Relationships for Scalar Properties in Nonpremixed Hydrocarbon/Air Flames," Combust. Flame, Vol. 82, 1990, pp. 211-230.

${ }^{11}$ Gore, J.P., and Faeth, G.M., "Structure and Spectral Radiation Properties of Turbulent Ethylene/Air Diffusion Flames," 21st Symposium (International) on Combustion, The Combustion Institute, Pittsburgh, PA, 1986, pp. 1521-1531.

${ }^{12}$ Gore, J.P., and Faeth, G.M., "Structure and Radiation Properties of Luminous Turbulent Acetylene/Air Diffusion Flames," J. Heat Trans., Vol. 110, 1988, pp. 173-181.

${ }^{13}$ Sunderland, P.B., Mortazavi, S., Faeth, G.M., and Urban, D.L., "Laminar Smoke Points of Nonbuoyant Jet Diffusion Flames," Combust. Flame, Vol. 96, 1994, pp. 97-103.

${ }^{14}$ Sunderland, P.B., Köylü, Ü.Ö., and Faeth, G.M., "Soot Formation in Weakly-Buoyant AcetyleneFueled Laminar Jet Diffusion Flames Burning in Air," Combust. Flame, Vol. 100, 1995, pp. 310-322.

${ }^{15}$ Sunderland, P.B., and Faeth, G.M., "Soot Formation in Hydrocarbon/Air Laminar Jet Diffusion 
Flames," Combust. Flame, Vol. 105, 1996, pp. 132146.

${ }^{16}$ Lin, K.-C., Sunderland, P.B., and Faeth, G.M., "Soot Nucleation and Growth in Acetylene/Air Laminar Coflowing Jet Diffusion Flames," Combust. Flame, Vol. 104, 1996, pp. 369-375.

${ }^{17}$ Santoro, R.J., Semerjian, H.B., and Dobbins, R.A., "Soot Particle Measurements in Diffusion Flames," Combust. Flame, Vol. 51, 1983, pp. 203-218.

${ }^{18}$ Santoro, R.J., Yeh, T.T., Horvath, J.J., and Semerjian, H.G., "The Transport and Growth of Soot Particles in Laminar Diffusion Flames," Combust. Sci. Tech., Vol. 53, 1987, pp. 89-115.

${ }^{19}$ Puri, R., Richardson, T.F., Santoro, R.J., and Dobbins, R.A., "Aerosol Dynamic Processes of Soot Aggregates in a Laminar Ethene Diffusion Flame," Combust. Flame, Vol. 92, 1993, pp. 320333.

${ }^{20}$ Puri, R., Santoro, R.J., and Smyth, K.C., "The Oxidation of Soot and Carbon Monoxide in Hydrocarbon Diffusion Flames," Combust. Flame, Vol. 97, 1994, pp. 125-144.

${ }^{21}$ Spalding, D. B., Combustion and Mass Transfer, Pergamon Press, New York, 1979, Chapt. 10.

${ }^{22}$ Mortazavi, S., Sunderland, P.B., Jurng, J., Köylü, Ü.Ö., and Faeth, G.M., "Structure of SootContaining Laminar Jet Diffusion Flames," AIAA Paper No. 93-0708, 1993.

${ }^{23}$ Haynes, B. S., and Wagner, H. G., "Soot Formation," Prog. Energy Combust. Sci., Vol. 7, 1981, pp. 229-273.

${ }^{24}$ Glassman, I., "Soot Formation in Combustion Processes," 22nd Symposium (International) on Combustion. The Combustion Institute, Pittsburgh, PA, 1988, pp. 295-311.

${ }^{25}$ Howard, J.B., "Carbon Addition and Oxidation Reactions in Heterogeneous Combustion and Soot Formation," 23rd Symposium (International) on Combustion, The Combustion Institute, Pittsburgh, PA, 1990, pp. 1107-1127.
${ }^{26} \mathrm{Jullien,}$ R., and Botet, R., Aggregation and Fractal Aggregates, World Scientific Publishing Co., Singapore, 1987.

${ }^{27}$ Kennedy, I.M., "Models of Soot Formation and Oxidation," Prog. Energy Combust. Sci., Vol. 23, 1997, pp. 95-132.

${ }^{28}$ Kono, M., Ito, K., Niioka, T., Kadota, T., and Sato, J., "Current State of Combustion Research in Microgravity," 26th Symposium (International) on Combustion, The Combustion Institute, Pittsburgh, PA, 1996, pp. 1189-1199.

${ }^{29}$ Kent, J.H., Jander, H., and Wagner, H.Gg., "Soot-Formation in a Laminar Diffusion Flame," 18th Symposium (International) on Combustion, The Combustion Institute, Pittsburgh, PA, 1980, pp. 11171126.

${ }^{30}$ Kent, J.H., and Wagner, H.Gg., "Soot Measurements in Laminar Ethylene Diffusion Flames," Combust. Flame, Vol. 47, 1982, pp. 53-65.

${ }^{31}$ Kent, J.H., and Wagner, H.Gg., "Why Do Diffusion Flames Emit Smoke?" Combust. Sci. Tech., Vol. 41, 1984, pp. 245-269.

${ }^{32}$ Kent, J.H., and Honnery, D.R., "A Soot Formation Rate Map for a Luminous Ethylene Diffusion Flame," Combust. Flame, Vol. 79, 1990, pp. 287-298.

${ }^{33}$ Honnery, D.R., and Kent, J.H., "Soot Formation in Long Ethylene Diffusion Flames," Combust. Flame, Vol. 82, 1990, pp. 426-434.

${ }^{34}$ Kent, J.H., and Honnery, D.R., "Soot Formation Rate in Diffusion Flames - A Unifying Trend," Combust. Sci. Tech.. Vol. 75, 1991, pp. 167177.

${ }^{35}$ Miller, J.H., Honnery, D.R., and Kent, J.H., "Modeling the Growth of Polynuclear Aromatic Hydrocarbons in Diffusion Flames," 24th Symposium (International) on Combustion, The Combustion Institute, Pittsburgh, PA, 1992, pp. 1031-1039.

${ }^{36}$ Honnery, D.R., Tappe, M., and Kent, J.H., "Two Parametric Models of Soot Growth Rates in Laminar Ethylene Diffusion Flames," Combust. Sci. Tech., Vol. 83, 1992, pp. 305-321. 
${ }^{37}$ Dobbins, R.A., and Megaridis, C.M. "Morphology of Flame-Generated Soot as Determined by Thermophoretic Sampling," Langmuir, Vol. 3, 1987, pp. 254-259.

${ }^{38}$ Megaridis, C.M., and Dobbins, R.A., "Soot Aerosol Dynamics in a Laminar Ethylene Diffusion Flame," 22nd Symposium (International) on Combustion, The Combustion Institute, Pittsburgh, PA, 1988, pp. 353-362.

${ }^{39}$ Megaridis, C.M., and Dobbins, R.A., "Comparison of Soot Growth and Oxidation in Smoking and Nonsmoking Ethylene Diffusion Flames," Combust. Sci. Tech. Vol. 66, 1989, pp. 116.

${ }^{40}$ Megaridis, C.M., and Dobbins, R.A., "Morphological Description of Flame-Generated Materials," Combust. Sci. Tech., Vol. 77, 1990, pp. 95-109.

${ }^{41}$ Dobbins, R.A., Fletcher, R.A., and Lee, W., "Laser Microprobe Analysis of Soot Precursor Particles and Carbonaceous Soot," Combust. Flame, Vol. 100, 1995, pp. 301-309.

${ }^{42}$ Flower, W.L., and Bowman, C.T., "Measurements of the Effect of Elevated Pressure on Soot Formation in Laminar Diffusion Flames," Combust. Sci. Tech., Vol. 37, 1984, pp. 93-97.

${ }^{43}$ Flower, W.L., and Bowman, C.T., "Measurements of the Structure of Sooting Laminar Diffusion Flames at Elevated Pressures," 20th Symposium (International) on Combustion, The Combustion Institute, Pittsburgh, PA, 1984, pp. 10351044.

${ }^{44}$ Flower, W.L., and Bowman, C.T., "Soot Production in Axisymmetric Laminar Diffusion Flames at Pressures from One to Ten Atmospheres," 21st Symposium (International) on Combustion, The Combustion Institute, Pittsburgh, 1986, pp. 11151124.

${ }^{45}$ Flower, W.L., and Bowman, C.T., "Observations on the Soot Formation Mechanism in Laminar Ethylene-Air Diffusion Flames at One and Two Atmospheres," Combust. Sci. Tech., Vol. 53, 1987, pp. 217-224.
${ }^{46}$ Schug, K.P., Manheimer-Timnat, Y., Yaccarino, P., and Glassman, I., "Sooting Behavior of Gaseous Hydrocarbon Diffusion Flames and the Influence of Additives," Combust. Sci. Tech., Vol. 22, 1980, pp. 235-250.

${ }^{47}$ Garo, A., Lahaye, J., and Prado, G., "Mechanisms of Formation and Destruction of Soot Particles in a Laminar Methane-Air Diffusion Flame," 21st Symposium (International) on Combustion, The Combustion Institute, Pittsburgh, PA, 1986, pp. 10231031.

${ }^{48}$ Garo, A., Prado, G., and Lahaye, J., "Chemical Aspects of Soot Particles Oxidation in a Laminar Methane-Air Diffusion Flame," Combust. Flame, Vol. 79, 1990, pp. 226-233.

${ }^{49}$ Saito, K., Gordon, A.S., Williams, F.A., and Stickle, W.F., "A Study of the Early History of Soot Formation in Various Hydrocarbon Diffusion Flames," Combust. Sci. Tech., Vol. 80, 1991, pp. 103-119.

${ }^{50} \mathrm{Xu}, \mathrm{F}$., Sunderland, P.B., and Faeth, G.M., "Soot Formation in Laminar Premixed Ethylene/Air Flames at Atmospheric Pressure," Combust. Flame, Vol. 108, 1997, pp. 471-493.

${ }^{51} \mathrm{Xu}, \mathrm{F}$. , Lin, K.-C., and Faeth, G.M., "Soot Formation in Laminar Premixed Methane/Oxygen Flames at Atmospheric Pressure," Combust. Flame, submitted.

${ }^{52}$ Köylü, Ü.Ö., and Faeth, G.M.,"Structure of Overfire Soot in Buoyant Turbulent Diffusion Flames at Long Residence Times," Combust. Flame, Vol. 89, 1992, pp. 140-156.

${ }^{53}$ Köylü, Ü.Ö., and Faeth, G.M., "Optical Properties of Overfire Soot in Buoyant Turbulent Diffusion Flames at Long Residence Times," I. Heat Trans., Vol. 116, 1994, pp. 152-159.

${ }^{54}$ Sivathanu, Y.R., and Faeth, G.M., "Temperature/Soot Volume Fraction Correlations in the Fuel Rich Region of Buoyant Turbulent Diffusion Flames," Combust. Flame, Vol. 81, 1990, pp. 150165.

${ }^{55}$ Cochran, T.H., and Masica, W.J., "An Investigation of Gravity Effects on Laminar Gas Jet Diffusion Flames," 13th Symposium (International) on 
Combustion, The Combustion Institute, Pittsburgh, PA, 1970, pp. 821-829.

${ }^{56}$ Haggard, J.B. Jr., and Cochran, T.H., "Stable Hydrocarbon Diffusion Flames in a Weightless Environment," Combust. Sci. Tech., Vol. 5, 1972, pp. 291-298.

${ }^{57}$ Edelman, R.B., Fortune, O.F., Weilerstein, G., Cochran, T.H., and Haggard, J.B., Jr., "An Analytical and Experimental Investigation of Gravity Effects upon Laminar Gas Jet-Diffusion Flames," 14th Symposium (International) on Combustion, The Combustion Institute, Pittsburgh, PA, 1972, pp. 399412.

${ }^{58}$ Klajn, M., and Oppenheim, A.K., "Influence of Exothermicity on the Shape of a Diffusion Flame," 19th Symposium (International) on Combustion, The Combustion Institute, Pittsburgh, PA, 1982, pp. 223235.

${ }^{59}$ Edelman, R.B., and Bahadori, M.Y., "Effects of Buoyancy on Gas-Jet Diffusion Flames: Experiment and Theory," Acta Astronautica, Vol. 13, 1986, pp. 681-688.

${ }^{60}$ Bahadori, M.Y., Edelman, R.B., Stocker, D.P., and Olson, S.L., "Ignition and Behavior of Laminar Gas-Jet Diffusion Flames in Microgravity," AIAA J., Vol. 28, 1990, pp. 236-244.

${ }^{61}$ Bahadori, M. Y., Stocker, D. P., and Edelman, R. B., "Effects of Pressure on Microgravity Hydrocarbon Diffusion Flames," AIAA Paper No. 900651, 1990.

${ }^{62}$ Bahadori, M.Y., Edelman, R.B., Sotos, R.G., and Stocker, D.P., "Radiation from Gas-Jet Diffusion Flames in Microgravity Environments," AIAA Paper 91-0719, 1991.

${ }^{63}$ Bahadori, M.Y., Edelman, R.B., Stocker, D.P. Sotos, R.G., and Vaughan, D.F., "Effects of Oxygen Concentration on Radiative Loss from NormalGravity and Microgravity Methane Diffusion Flames," AIAA Paper No. 92-0243, 1992.

${ }^{64}$ Dalzell, W.H., and Sarofim, A.F., "Optical Constants of Soot and Their Application to Heat Flux Calculations," J. Heat Trans., Vol. 91, 1969, pp. 100104.
${ }^{65}$ Wu, J.-S., Krishnan, S.S., and Faeth, G.M., "Refractive Indices at Visible Wavelengths of Soot Emitted from Buoyant Turbulent Diffusion Flames," J. Heat Trans., Vol. 119, 1997, pp. 230-237.

${ }^{66}$ Rosner, D.E., Mackowski, D.W., and GarciaYbarra, P., "Size- and Structure-Insensitivity of the Thermophoretic Transport of Aggregated 'Soot' Particles in Gases," Combust. Sci. Tech., Vol. 80, 1991, pp. $87-101$.

${ }^{67}$ Samson, R. J., Mulholland, G. W., and Gentry, J. W., (1987) Structural Analysis of Soot Agglomerates," Langmuir Vol. 3, 1987, pp. 272-281.

${ }^{68}$ Köylü, Ü.Ö., and Faeth, G.M., "Optical Properties of Soot in Buoyant Laminar Diffusion Flames," J. Heat Trans., Vol. 116, 1994, pp. 971-979.

${ }^{69}$ Köylü, Ü.Ö., Faeth, G.M., Farias, T.L., and Carvalho, M.G., "Fractal and Projected Structure Properties of Soot Aggregates," Combust. Flame, Vol. 100, 1995, pp. 621-633.
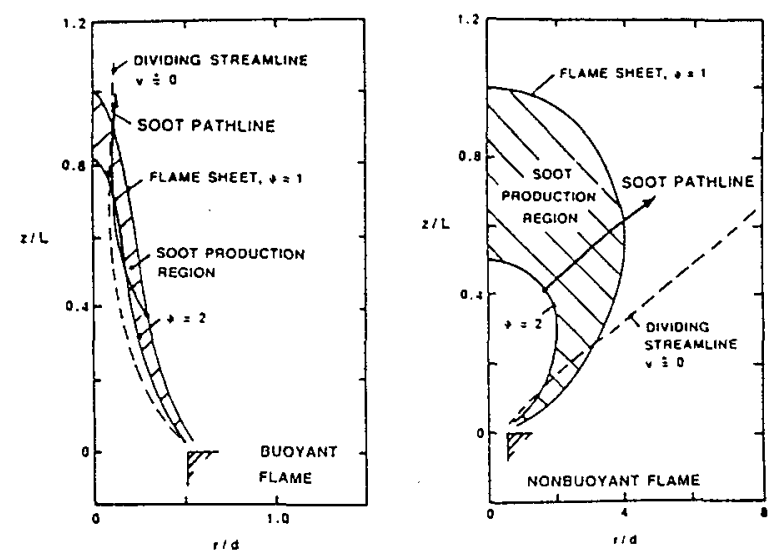

Fig. 1 Sketches of flame shapes, soot production regions, dividing streamlines and soot pathlines in buoyant and nonbuoyant laminar jet diffusion flames. The stoichiometric mixture fraction is 0.07 . 
Table 1 Summary of test conditions $\mathrm{s}^{\mathrm{a}}$

\begin{tabular}{|c|c|c|}
\hline Test & $01 \mathrm{E}$ & $02 \mathrm{E}$ \\
\hline $\begin{array}{l}\text { Nominal test } \\
\text { pressure }(\mathrm{kPa})\end{array}$ & 100 & 50 \\
\hline $\begin{array}{l}\text { Steady burning } \\
\text { period }(s)^{b}\end{array}$ & $18-230$ & $20-175$ \\
\hline Fuel flow rate $(\mathrm{mg} / \mathrm{s})$ & 1.84 & 1.84 \\
\hline $\begin{array}{l}\text { Avg. burner exit } \\
\text { density }\left(\mathrm{kg} / \mathrm{m}^{3}\right)^{\mathrm{c}}\end{array}$ & 1.12 & 0.56 \\
\hline $\begin{array}{l}\text { Avg. burner exit } \\
\text { velocity }(\mathrm{mm} / \mathrm{s})^{\mathrm{c}}\end{array}$ & 815 & 1630 \\
\hline $\begin{array}{l}\text { Burner exit Reynolds } \\
\text { number }(-)\end{array}$ & 141 & 141 \\
\hline $\begin{array}{l}\text { Chamber oxygen } \\
\text { concentration (\% by vol. })^{d}\end{array}$ & $21.2-20.1$ & $21.2-19.4$ \\
\hline Chamber pressure ( $\mathrm{kPa})$ & $104.0-105.0$ & $52.5-53.5$ \\
\hline Chamber temperature (K) & $301-302$ & 301-302 \\
\hline $\begin{array}{l}\text { Flame radiant heat } \\
\text { flux }\left(\mathrm{kW} / \mathrm{m}^{2}\right)\end{array}$ & 0.62 & 0.58 \\
\hline $\begin{array}{l}\text { Flame radiative heat } \\
\text { loss function (\% LHV) }\end{array}$ & 60 & 56 \\
\hline $\begin{array}{l}\text { Luminous flame } \\
\text { length (mm) }\end{array}$ & $49-52$ & $63-64$ \\
\hline $\begin{array}{l}\text { Maximum luminous } \\
\text { flame diameter (mm) }\end{array}$ & 14 & 14 \\
\hline $\begin{array}{l}\text { Characteristic flame } \\
\text { residence time (ms) }\end{array}$ & 124 & 78 \\
\hline $\begin{array}{l}\text { Maximum soot } \\
\text { concentration (ppm) }\end{array}$ & 32.0 & 2.1 \\
\hline $\begin{array}{l}\text { Avg. primary soot } \\
\text { particle diameter (nm) }\end{array}$ & 40 & 24 \\
\hline
\end{tabular}

aExperiments carried out on space shuttle Columbia (flight STS-83) with ethylene as the fuel: $1.6 \mathrm{~mm}$ burner diameter, initial fuel flow rate of $2.6 \mathrm{mg} / \mathrm{s}$, sootemitting, soot samples obtained, ranges shown correspond to beginning and end of soot sampling period, $\mu_{\mathrm{o}}=1.03 \times 10^{-5} \mathrm{~kg} /(\mathrm{ms})$ at $300 \mathrm{~K}, \mathrm{LHV}=$ $47,158 \mathrm{~kJ} / \mathrm{kg}$ fuel.

${ }^{\mathrm{b}}$ Times of beginning and end of steady burning period relative to the time of ignition.

'Based on nominal pressure and $300 \mathrm{~K}$.

${ }^{d}$ Initially simulated dry air as an $\mathrm{O}_{2} / \mathrm{N}_{2}$ mixture.

eMeasured at a distance of $80.5 \mathrm{~mm}$ from the flame axis.

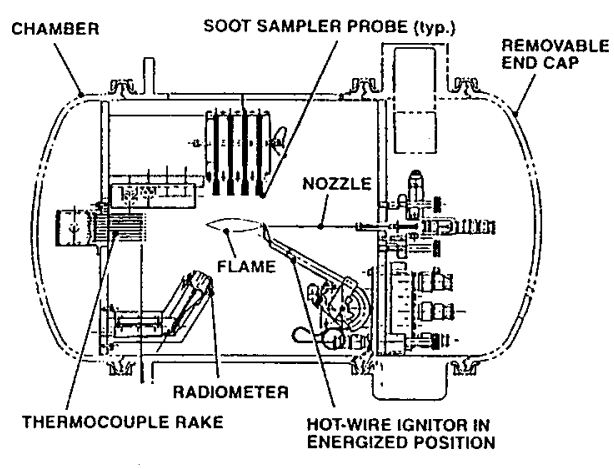

Fig. 2 Sketch of the laminar soot processes (LSP) test apparatus for observations of nonbuoyant round laminar jet diffusion flames.

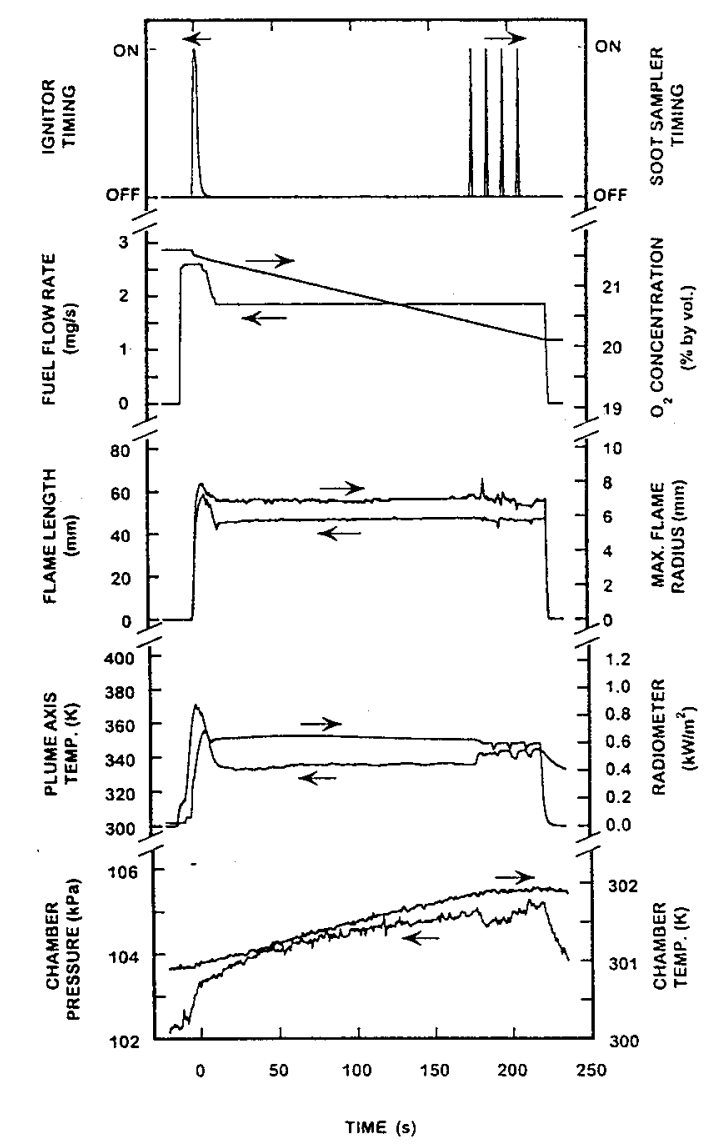

Fig. 3 Monitoring measurements as a function of time for the $100 \mathrm{kPa}$ flame: ignitor and soot sampler timing, fuel flow rate, ambient oxygen concentration. luminous flame length, maximum luminous flame radius, plume axis temperature, radiometer output, chamber pressure, and chamber temperature. 


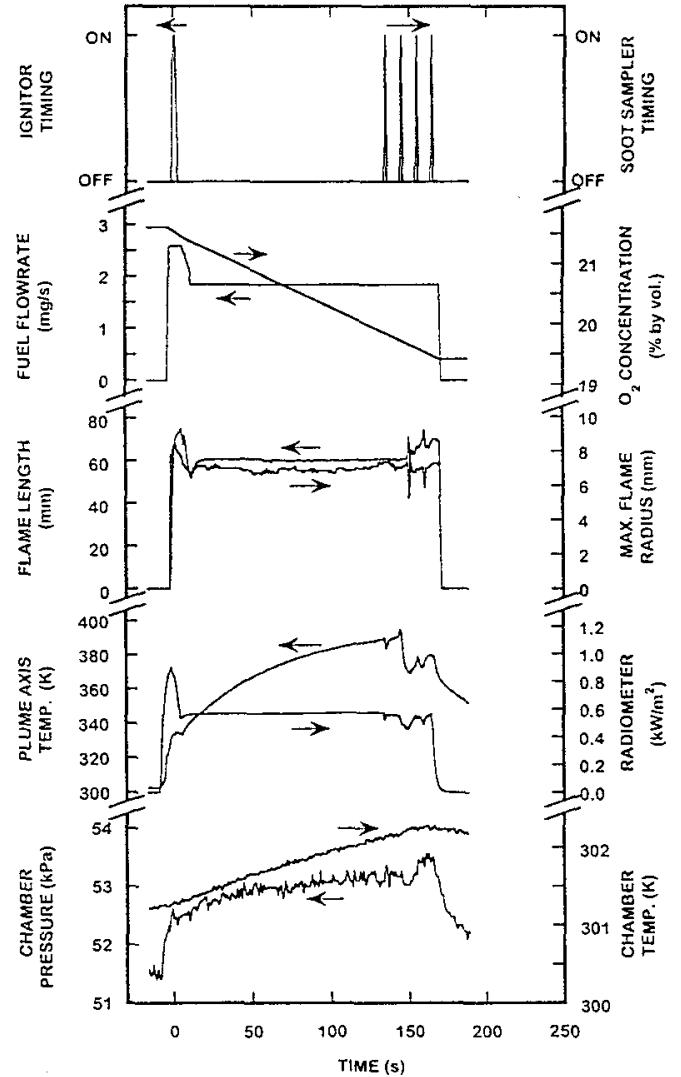

Fig. 4 Monitoring measurements as a function of time for the $50 \mathrm{kPa}$ flame: ignitor and soot sampler timing, fuel flow rate, ambient oxygen concentration, luminous flame length, maximum luminous flame radius, plume axis temperature, radiometer output, chamber pressure, and chamber temperature.

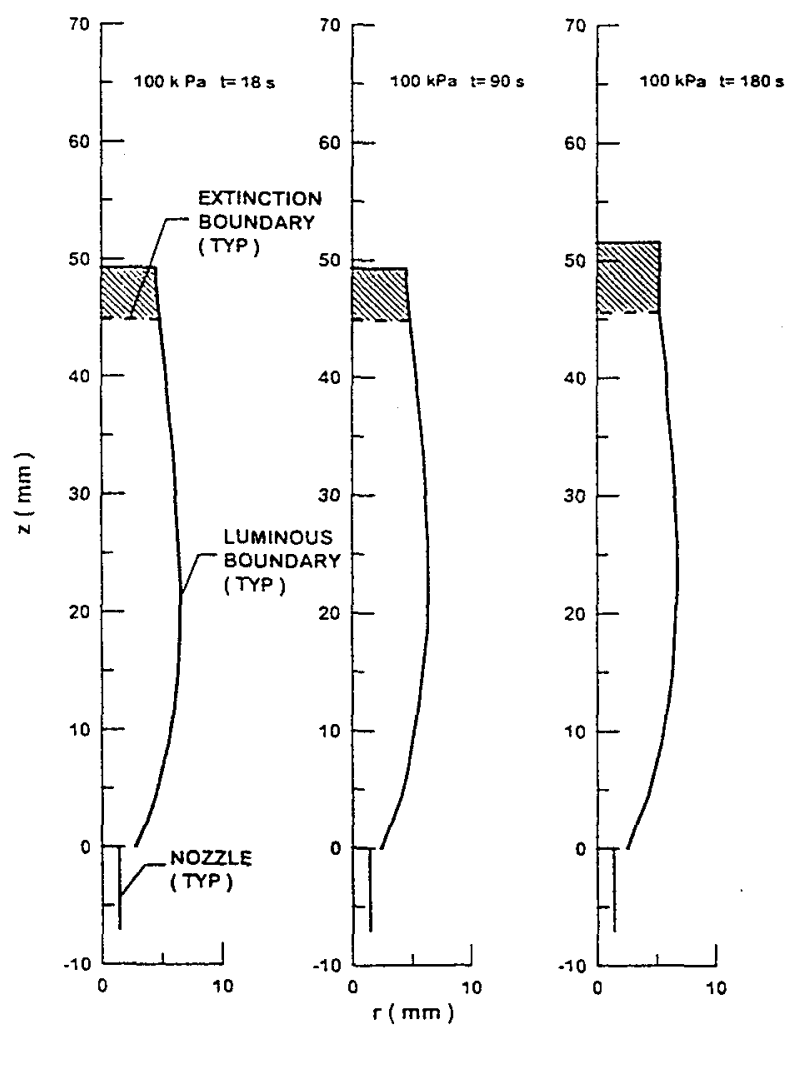

Fig. 6 Sketch of the luminous flame boundaries of the $100 \mathrm{kPa}$ flame at 18,90 and $180 \mathrm{~s}$ after the time of ignition.

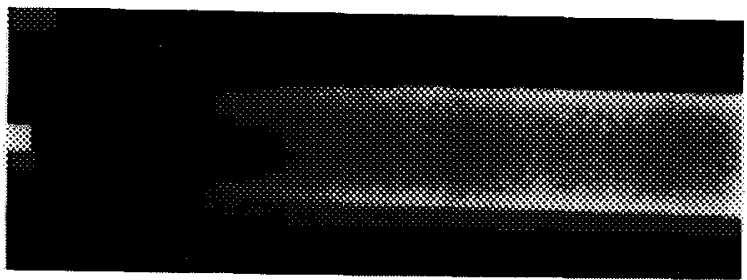

Fig. 7 Laser extinction image of the $100 \mathrm{kPa}$ flame during the image sampling period (maximum image diameter is $14 \mathrm{~mm}$ ). 


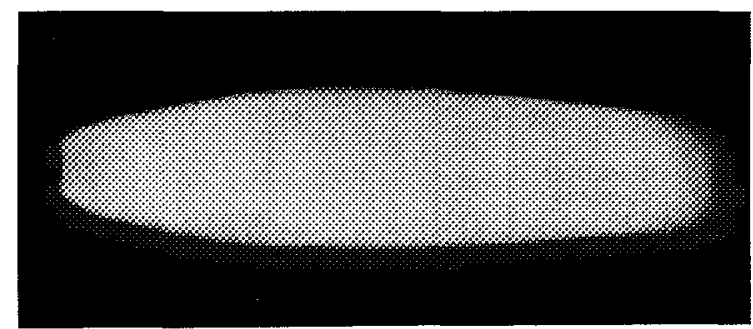

Fig. 8 Color video image of the $50 \mathrm{kPa}$ flame during the image sampling period (maximum luminous flame diameter is $14 \mathrm{~mm}$ ).
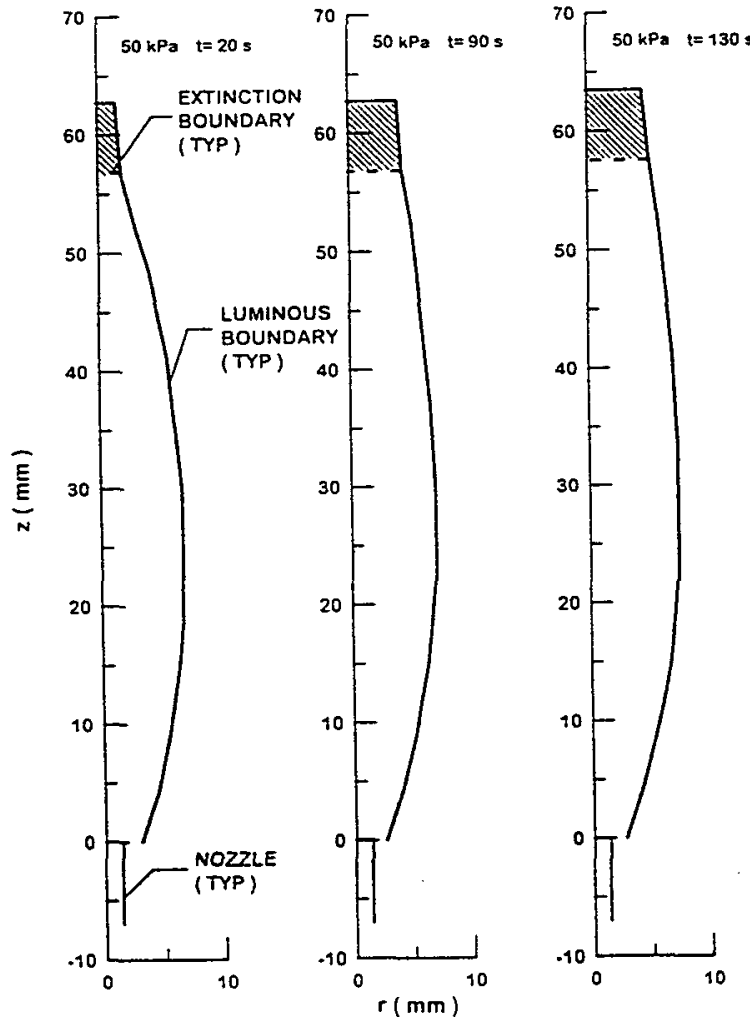

Fig. 9 Sketch of the luminous flame boundaries of the $50 \mathrm{kPa}$ flame at 20,90 and $130 \mathrm{~s}$ after the time of ignition.

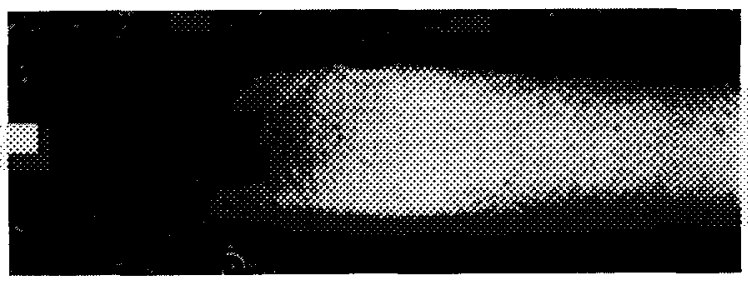

Fig. 10 Laser extinction image of the $50 \mathrm{kPa}$ flame during the image sampling period (maximum image diameter is $14 \mathrm{~mm}$ ).

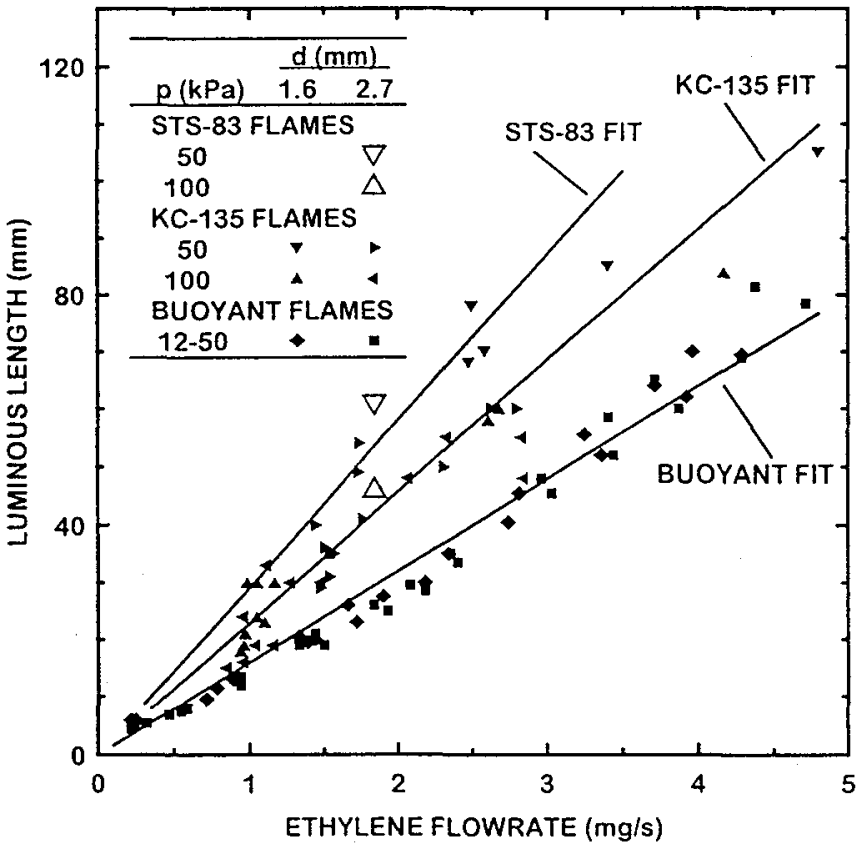

Fig. 11 Luminous flame lengths of nonbuoyant and buoyant ethylene/air round laminar, jet diffusion flames as a function of fuel flow rate, burner diameter and pressure. 
Table 2 Summary of laminar smoke point flame lengths $(\mathrm{mm})^{\mathbf{a}}$

\begin{tabular}{llll}
$\begin{array}{l}\text { Burner } \\
\text { Diameter } \\
(\mathrm{mm})\end{array}$ & \multicolumn{2}{l}{ Nominal Pressure (kPa) } \\
\cline { 2 - 4 } & 50 & 100 & 200
\end{tabular}

Nonbuoyant (space-based) present measurements:
1.6
$<63<49 \quad-$

Nonbuoyant (ground-based) measurements of Sunderland et al.: ${ }^{13}$

$\begin{array}{llll}1.6 & 85 & 36 & - \\ 2.7 & 80 & 25 & 13 \\ 5.9 & 110 & 28 & 13\end{array}$

Buoyant measurements of Schug et al. ${ }^{46}$ and Sivathanu and Faeth: ${ }^{54}$

10.0 - $162-169 \quad-$

${ }^{2}$ Laminar round jet ethylene/air flames at normal temperature (roughly $300 \mathrm{~K}$ ).

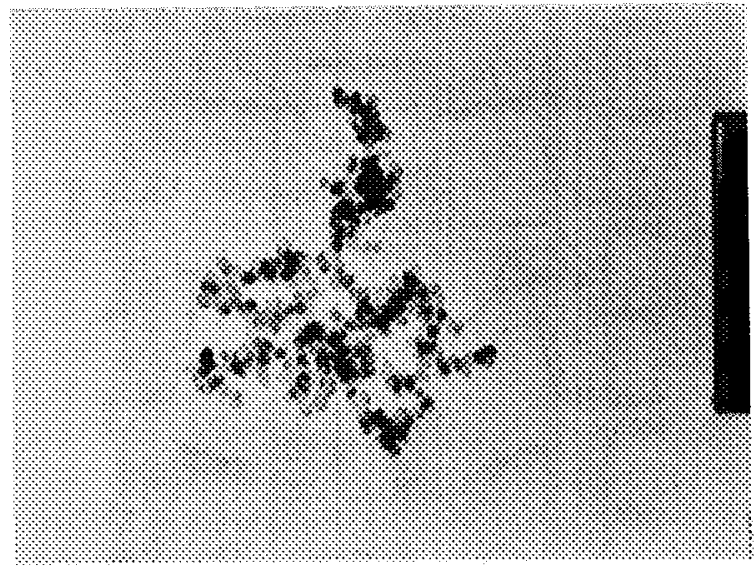

Fig. 12 TEM photograph of a typical soot aggregate in the $100 \mathrm{kPa}$ flame from within the soot layer beyond the flame tip $(z=59 \mathrm{~mm})$. Note the maximum dimension of the aggregate is roughly 1100 nm.

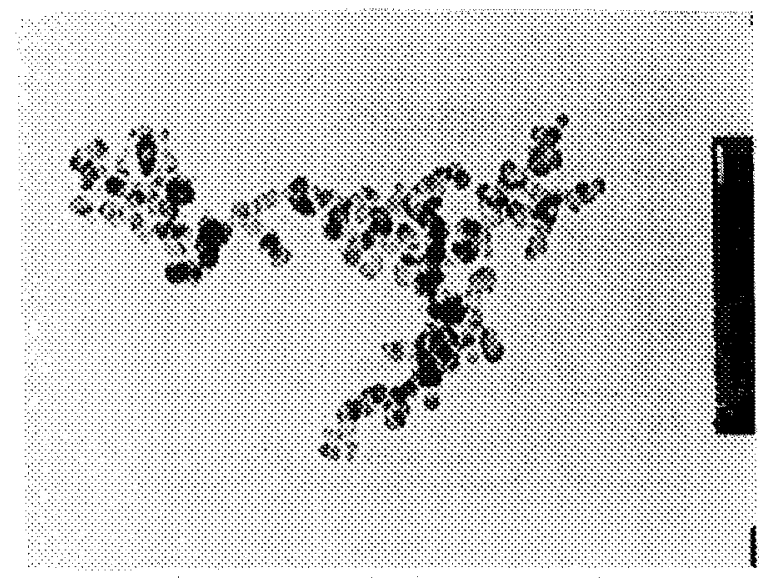

Fig. 13 TEM photograph of a typical soot aggregate in the $50 \mathrm{kPa}$ flame from within the soot layer beyond the flame tip $(z=80 \mathrm{~mm})$. Note the maximum dimension of the aggregate is roughly 600 $\mathrm{nm}$.

Table 3 Summary of primary soot particle diameters $(\mathrm{nm})^{\mathrm{a}}$

Streamwise

Test (Pressure)

Distance

(mm)

\begin{tabular}{ll}
\hline $01 \mathrm{E}$ & $02 \mathrm{E}$ \\
$(100 \mathrm{kPa})$ & $(50 \mathrm{kPa})$
\end{tabular}

15

39

37

45

27

59

39

23

80

38

22

\section{Average}

40

24

${ }^{2}$ Experiments carried out on Space Shuttle Columbia (flight STS-83) with ethylene/air flames: $1.6 \mathrm{~mm}$ burner diameter. 


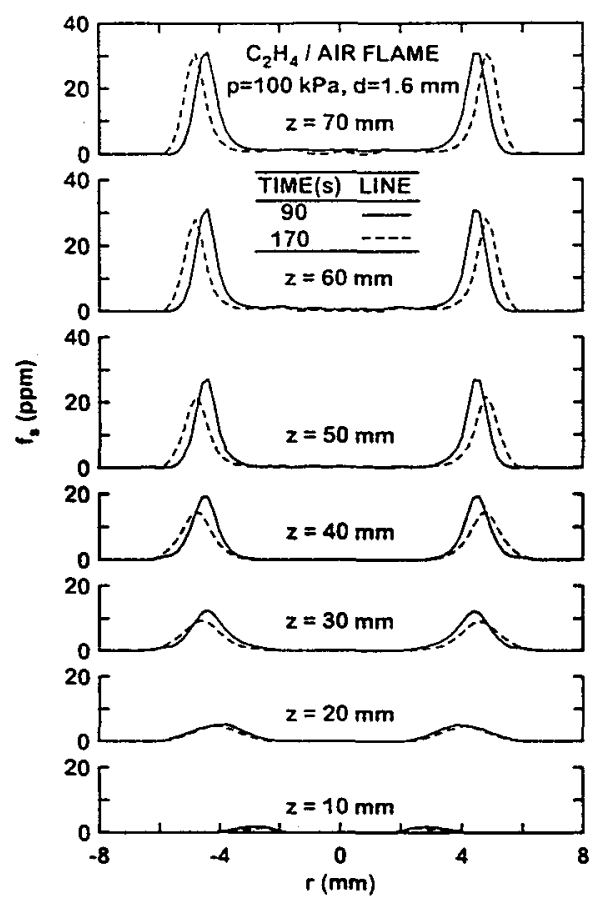

Fig. 14 Soot volume fraction distributions in the $100 \mathrm{kPa}$ flame at 90 and $170 \mathrm{~s}$ after the time of ignition for various distances from the burner exit.

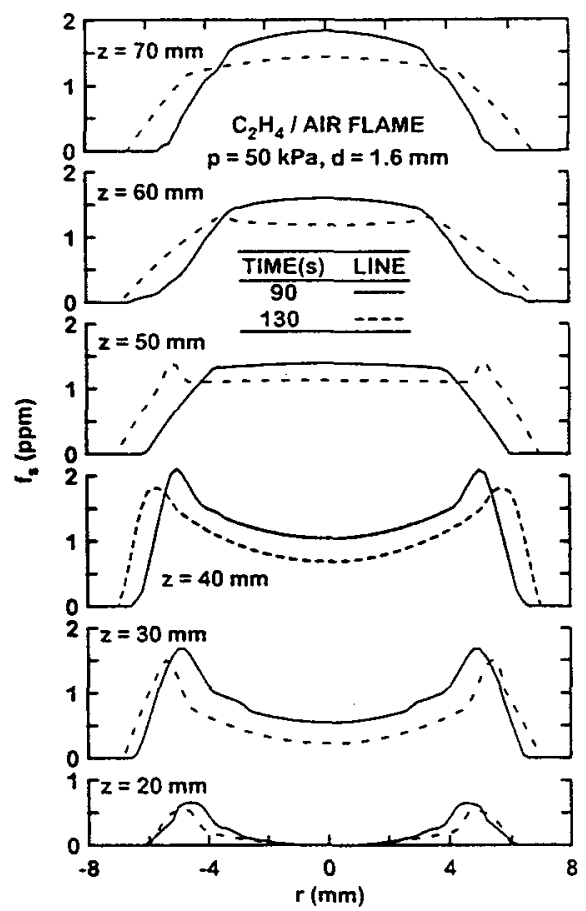

Fig. 15 Soot volume fraction distributions in the $50 \mathrm{kPa}$ flame at 90 and $130 \mathrm{~s}$ after the time of ignition for various distances from the burner exit.

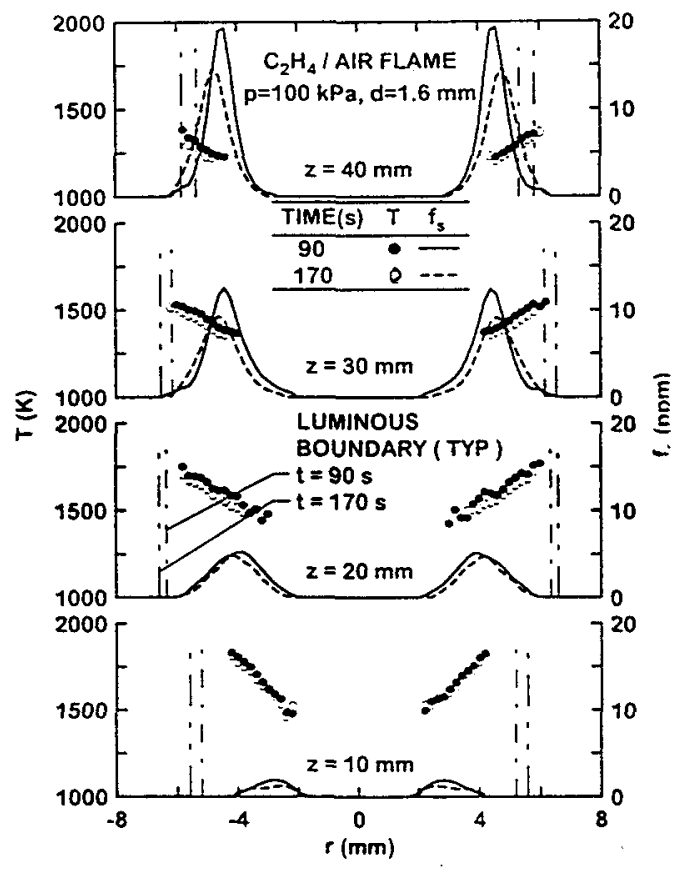

Fig. 16 Soot temperature and volume fraction distributions in the $100 \mathrm{kPa}$ flame at 90 and $170 \mathrm{~s}$ after the time of ignition for various distances from the burner exit.

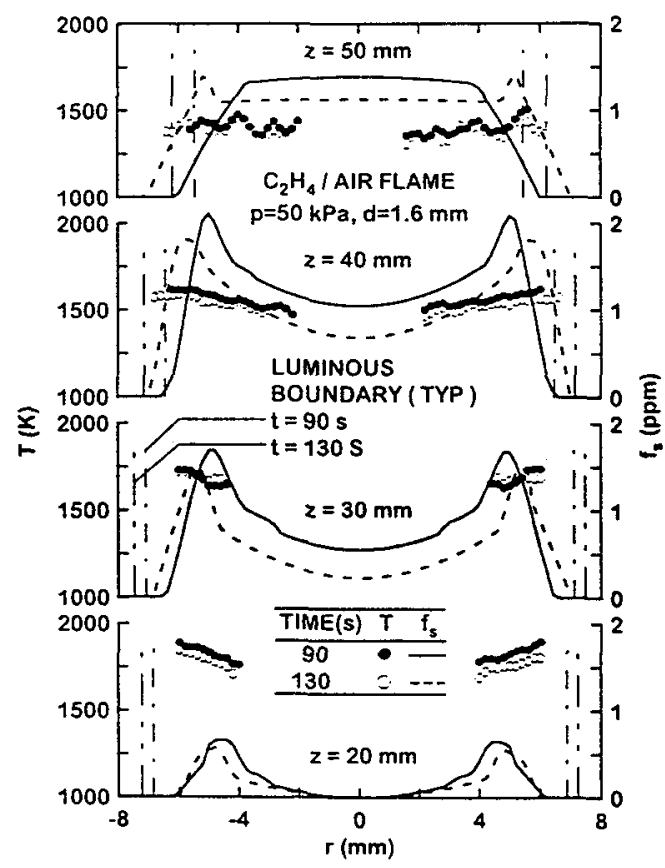

Fig. 17 Soot temperature and volume fraction distributions in the $50 \mathrm{kPa}$ flame at 90 and $130 \mathrm{~s}$ after the time of ignition for various distances from the burner exit. 


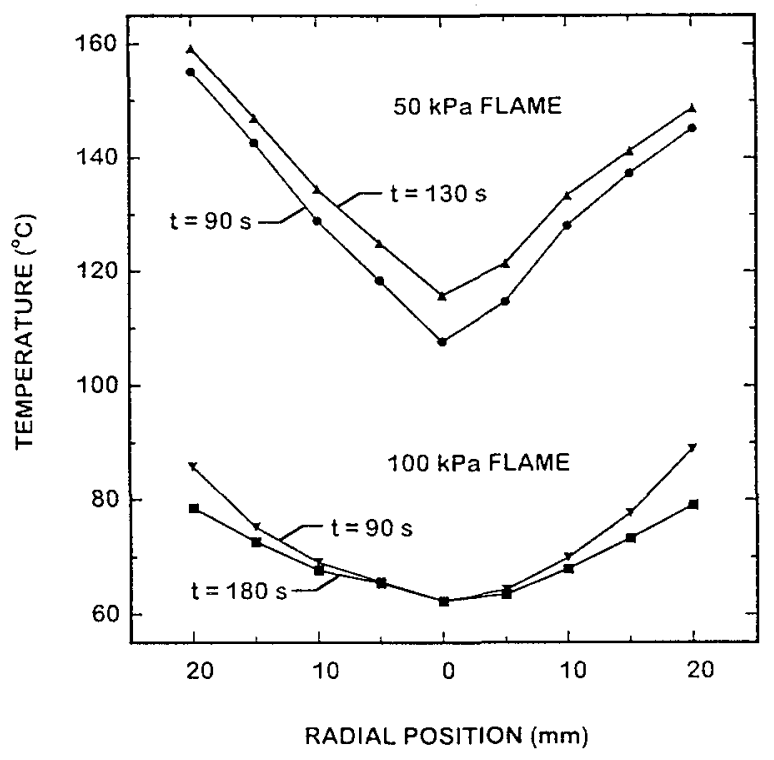

Fig. 18 Plume temperature distributions $(z=150$ $\mathrm{mm}$ ) at the beginning and end of the image sampling period for the 100 and $50 \mathrm{kPa}$ flames. 